\title{
Um modelo setorial baseado na abordagem kaleckiana da distribuição setorial funcional da renda e na teoria schumpeteriana da concorrência *
}

\author{
Tatiana Massaroli Melo ${ }^{* *}$ \\ Mario Luiz Possas *** \\ Esther Dweck ${ }^{* * * *}$
}

\section{Resumo}

Este artigo utiliza um referencial teórico schumpeteriano e kaleckiano para apresentar um modelo setorial capaz de captar os efeitos dinâmicos das inovações sobre a competitividade e a distribuição setorial funcional da renda. Adota-se a teoria distributiva de Kalecki, segundo a qual a distribuição funcional da renda é vinculada ao processo de formação de preços por mark-up. É desenvolvido um modelo de simulação para as interações entre firmas dentro de setores específicos a partir do método Agent-based modelling. A principal conclusão é que os resultados obtidos pelas simulações mostram que as inovações tecnológicas, ao influenciarem preço e mark-up, afetam diretamente a distribuição.

Palavras-chave: Modelo setorial; Distribuição funcional da renda; Processo de concorrência; Kalecki; Schumpeter.

\section{Abstract \\ A sectoral model based on the Kaleckian approach of sectoral functional income distribution and the Schumpeterian theory of competition}

This article uses the schumpeterian and kaleckian theories to present a sectoral model able to capture the dynamic effects of innovation on competitiveness and sectoral functional income distribution. Kalecki's distribution theory, according to which the functional income distribution is linked to markup pricing, is adopted. A simulation model for interaction between companies within specific sectors is developed from agent-based modelling. The main conclusion drawn from the results obtained with simulations shows that technological innovations directly affect income distribution by influencing both price and markup.

Keywords: Sectoral model; Functional distribution of income; Competition process; Kalecki; Schumpeter.

JEL B520, O300, O390.

* Artigo recebido em 14 de julho de 2013 e aprovado em 8 de janeiro de 2016.

** Professora do Departamento de Economia da Universidade Estadual Paulista "Júlio de Mesquita Filho" (UNESP), Araraquara, SP, Brasil. E-mail: tmassaroli@fclar.unesp.br.

*** Professor do Instituto de Economia (IE) da Universidade Federal do Rio de Janeiro (UFRJ), Rio de Janeiro, RJ, Brasil. E-mail: mariopossas@gmail.com.

${ }^{* * * *}$ Professora do Instituto de Economia (IE/UFRJ), Rio de Janeiro, RJ, Brasil. E-mail: esther.dweck@gmail.com. 


\section{Introdução}

Este artigo é definido a partir de um referencial teórico schumpeteriano e kaleckiano para analisar os efeitos dinâmicos da inovação de produto sobre a competitividade e a distribuição funcional da renda no nível setorial. A análise destes efeitos é realizada a partir da identificação dos determinantes das inovações tecnológicas endógenos ao processo competitivo e ao acúmulo de conhecimento dentro da firma, o qual é expresso em rotinas que direcionam parcialmente o processo de busca tecnológica para a solução de problemas específicos (Dosi, 1988; Nelson; Winter, 1982). Os processos de busca, dirigidos pelas rotinas da firma ou modificadores de rotinas, têm como consequência o reforço da posição oligopolística da firma, traduzida em aumento do mark-up desejado e do market share.

Regras e rotinas de comportamento coordenam o processo competitivo em diferentes estruturas de mercado, desde aquelas em que a concorrência se desenvolve sob condições de pouca complexidade. Por exemplo, a baixa diferenciação de produtos viabilizando estratégias competitivas bastante simples, como a competição em preço, até os mercados caracterizados por maior complexidade. Quanto mais complexo o ambiente em que a competição se desenvolve, isto é, alta diferenciação de produto, sofisticação dos processos produtivos envolvidos e incerteza forte acerca dos resultados de determinada ação, maior a importância relativa da inovação tecnológica como estratégia competitiva.

As inovações tecnológicas, sejam de produto ou de processo, tendem a afetar a distribuição funcional setorial da renda na medida em que ampliam as assimetrias entre as firmas, aumentando as diferenças entre firmas inovadoras e imitadoras. A análise dos efeitos da combinação de inovações de processo e produto sobre a dinâmica competitiva de setores específicos é realizada a partir do comportamento do market share das firmas que compõem o setor, da capacidade destas de manter mark-ups elevados, do grau de concentração do setor, bem como da distribuição funcional da renda no nível setorial. Apesar de reconhecer a importância conjunta dos efeitos dos dois tipos de inovação, espera-se que as inovações de produto exerçam maior impacto sobre a dinâmica competitiva dos setores, em função do reconhecimento deste tipo de inovação como elemento fundamental no processo de mudança tecnológica (Verona; Ravasi, 2003; Dougherty, 1992; Nonaka, 1994; Saviotti, 2001; Daneels, 2002). Ao flexibilizar o trade off entre mark-up e market share, a inovação de produto permite a substituição da concorrência em preço pela concorrência em diferenciação, ampliando as vantagens competitivas das firmas inovadoras. A criação de novos produtos é o elemento central utilizado pelas organizações para se adaptarem ou mesmo modificarem seu ambiente de atuação (Eisenhardt; Trabizi, 1996). Nas indústrias de alta tecnologia, a competição é fortemente baseada em diferenciais de desempenho do produto. Em contrapartida, em indústrias tecnologicamente maduras, a necessidade de redução de custo, em 
virtude da competição em preço, tende a concentrar os gastos de $\mathrm{P} \& \mathrm{D}$ em inovações de processo (Pleatska; Teece, 2001). Ademais, as inovações de produto representam trajetórias observáveis de mudança técnica incremental provenientes de processos de aprendizado não observados, tais como learning by searching e learning by interacting (Corsino; Gabriele, 2010; Malerba, 1992).

Em indústrias mais intensivas em inovação de produto, o crescente uso de diferenciação vertical de produtos e as mudanças periódicas de paradigmas tecnológicos tendem a mudar rapidamente parcelas de mercado preexistentes, emergindo novas lideranças. Dessa forma, a competição em indústrias de alta tecnologia e intensivas em inovação de produto é mais intensa que a competição nas indústrias maduras e intensivas em inovação de processo (Pleatska; Teece, 2001).

A obtenção de rendas diferenciais a partir de um processo dinâmico de introdução de inovações bem-sucedidas pode culminar no surgimento de maior variedade e diversidade setorial, promovendo mudanças endógenas na composição do sistema econômico. Neste cenário, setores cujo desempenho tecnológico se assemelha àquele da fronteira tecnológica tendem a apresentar maior chance de sobrevivência, dada a alta taxa de introdução de inovações observada. Dessa forma, é possível que trabalho e outros recursos produtivos possam ser deslocados de setores antigos, menos dinâmicos tecnologicamente, para os novos setores, mais dinâmicos (Saviotti, 2001; Saviotti; Pika, 2008).

A análise das interações entre as diferentes firmas em setores estilizados é feita a partir de um método de modelagem baseado em agentes - Agent-Based Modelling (ABM). O uso da modelagem baseada em agentes é justificado pelo fato de aprendizado e interação serem elementos centrais para a compreensão de sistemas complexos (Storper, 1996; Dosi et al., 1990). Portanto, a dinâmica competitiva e o processo de mudança tecnológica não podem ser compreendidos a partir de modelos analíticos, baseados em exercícios de estática comparativa e nos pressupostos de equilíbrio e obtenção de resultados maximizadores, mas como um processo que, constantemente, gera mudanças entre os atores econômicos ao longo do tempo (Nelson; Winter, 1982; Dosi, 1988; Dosi et al., 1997). Neste tipo de abordagem o agente representa as partes que constituem o sistema, definidas a partir de regras de comportamento e dados iniciais, com capacidade de tomar decisões e aprender (Dawid, 2005; Arthur, 2005).

Em relação ao método de simulação, observa-se sua crescente aplicação na economia, apesar das críticas ao seu emprego (Cyert; March, 1963; Valente, 1999; Axelrod, 2005). A principal crítica ao uso de simulações diz respeito à liberdade associada à técnica, levando à falta de rigor na formulação do modelo e na interpretação dos resultados. No entanto, esta crítica é errônea, pois a liberdade dos modelos de simulação é fundamental para a compreensão de sistemas complexos, na 
medida em que torna o instrumental metodológico compatível com as características do objeto de análise, e não o contrário, como ocorre com os modelos analíticos (Valente, 1999; Dawid, 2005; Garson, 2009)

O modelo aqui utilizado foi originalmente desenvolvido em Possas (1983) e Possas, Koblitz et al. (2001). Algumas alterações foram realizadas em relação ao modelo original, tais como: (i) introdução de inovação de produto; (ii) o salário passa a ser determinado endogenamente, possibilitando a análise da distribuição setorial funcional da renda; (iii) a demanda do setor torna-se parcialmente endógena, sendo influenciada pela inovação de produto. Dentre os elementos da dinâmica industrial, destacam-se algumas variáveis setoriais que possuem implicação distributiva: (i) market share; (ii) concentração industrial; (iii) distribuição de renda (salários/renda); (iv) excedente bruto. O modelo é essencialmente teórico, no sentido de que não incorpora dados reais (embora os dados utilizados nas simulações sejam empiricamente plausíveis), e está baseado em microfundamentos schumpeterianos e kaleckianos, com os quais pretende explicar a dinâmica setorial como resultado das interações das firmas.

\section{Estrutura do modelo}

Neste trabalho, os impactos das inovações de produto sobre a competitividade e a distribuição entre salários e lucros no nível da firma serão analisados a partir da comparação entre setores estilizados. Em todos os cenários os setores serão constituídos de firmas inovadoras e imitadoras, que realizam inovações de produto e processo. Os fatores que diferenciam os setores nos diversos cenários simulados são: (i) a intensidade dos gastos em $\mathrm{P} \& \mathrm{D}$ destinados à inovação de produto e inovação de processo; (ii) diferenças setoriais entre os coeficientes de elasticidade-preço e elasticidade-qualidade da competitividade, com maior peso do primeiro em relação ao segundo no caso de o setor ser mais intensivo em inovação de processo, e vice-versa para um setor mais intensivo em inovação de produto. A diferença das elasticidades informará acerca da estratégia competitiva predominante em cada setor, isto é, se a competição em inovação de produto é mais ou menos intensa em relação à inovação de processo.

Em relação à estratégia competitiva em preços, como firmas mais inovadoras tendem a serem líderes de preço, enquanto firmas mais imitativas tendem a ser seguidoras de preço, um fator que diferenciará as empresas dentro do mesmo setor é a importância dada ao mark-up desejado e ao mark-up efetivo na determinação do preço. No caso de firmas mais inovadoras, a escolha do preço praticado será tal que o preço desejado (e portanto o mark-up desejado) terá maior peso que o preço de mercado, o inverso ocorrendo com firmas mais imitadoras. Dessa forma, os cenários a serem simulados compreenderão basicamente dois tipos de setores: (1) setores intensivos em inovação de produto; (2) setores intensivos em inovação de processo. 
Os setores serão estilizados com base na trajetória tecnológica de suas firmas, cuja principal fonte de tecnologia é a atividade de $\mathrm{P} \& \mathrm{D}$. As inovações introduzidas pelas firmas do primeiro tipo de setor, associadas em grande parte ao desenvolvimento das ciências básicas, têm um efeito positivo sobre sua competitividade, permitindo ampliação do mark-up e da parcela dos lucros na renda sem comprometer o market share. O desenvolvimento das ciências básicas tende a promover maior dinamismo competitivo, já que os resultados de pesquisa produzidos na área de ciências básicas permitem a criação de produtos e mercados genuinamente novos. No caso dos setores do segundo grupo, as inovações de processo introduzidas pelas firmas geram ganhos de produtividade e redução de custos que, ao serem repassados para os preços, permitem elevação do market share, embora este aumento não seja necessariamente acompanhado por elevação do mark-up. Os benefícios econômicos do progresso técnico serão distribuídos entre os salários e os lucros de cada setor de acordo com a estratégia tecnológica de suas firmas e seus efeitos diretos e indiretos ao longo do tempo, conforme será detalhado mais à frente.

A escolha de setores estilizados é parte do objetivo de construir um modelo teórico capaz de explicar a dinâmica da economia como um sistema complexo adaptativo evolucionário. Particularidades históricas, nacionais e institucionais, como já assinalado, não serão consideradas explicitamente, mas em versões posteriores poderão ser tratadas como parâmetros ou variáveis exógenas ao modelo (Possas, 1983). Com o intuito de permitir uma análise dinâmica, deverão ser incorporados ao modelo os mecanismos pelos quais as firmas tentam se adaptar ao ambiente. Em Possas, Koblitz et al. (2001), os mecanismos adaptativos podem ser incorporados à análise pela introdução de elementos tais como: aspectos relativos à demanda efetiva nas decisões de produção e investimento; uso de uma equação de preços em que o mark-up desejado está sujeito a mudanças endógenas em virtude das avaliações estratégicas das firmas; restrições financeiras relativas à decisão de investir; entre outros. Seguindo a metodologia adotada no modelo evolucionário setorial desenvolvido por Possas, Koblitz et al. (2001) e utilizada em Dweck (2006), tais elementos são estruturados em quatro blocos de equações, sendo o quarto introduzido de forma explícita para efeito deste trabalho:

Bloco 1: determinação das variáveis produção, preços e lucros;

Bloco 2: determinação das decisões de investimento;

Bloco 3: determinação dos procedimentos de busca tecnológica;

Bloco 4: geração e distribuição da renda no nível setorial.

No modelo de Possas, Koblitz et al. (2001), as decisões de produção e investimento são tomadas considerando o princípio da demanda efetiva, o que implica a distinção entre produção e vendas e ausência de equilíbrio como postulado. Os preços são determinados a partir da média ponderada entre preço médio desejado 
e preço médio do mercado. O preço médio desejado é definido pelo mark-up desejado e custos variáveis, sendo o mark-up desejado sujeito a variações endógenas devidas a avaliações estratégicas e restrições financeiras no âmbito das decisões de investir. Os setores simulados nos diferentes cenários, diferenciados pelo grau de intensidade tecnológica, são caracterizados como oligopólios em que a concorrência se dá via preço e diferenciação de produtos. Nos setores mais intensivos em inovação de processo, a concorrência via preço será mais intensa que a concorrência em diferenciação de produtos (e vice-versa), o que é operacionalizado no modelo por meio de mudanças nos parâmetros de elasticidade da competitividade em relação a preço $\left(\varepsilon_{\mathrm{p}}\right)$ e elasticidade da competitividade em relação à qualidade $\left(\varepsilon_{\mathrm{q}}\right)$.

\section{Equações do modelo}

\subsection{Bloco 1a: demanda e decisões de produção}

\subsubsection{Demanda}

Em virtude de este ser um modelo setorial, a demanda e seu crescimento são determinados exogenamente. No entanto, a existência de inovação de produto faz com que o crescimento da demanda seja em parte determinado endogenamente, dado que os setores mais intensivos em inovação de produto, ao criarem novos segmentos de atuação, ou novos mercados, permitem que a demanda se ajuste à inovação ${ }^{1}$, frente a uma inovação de produto bem sucedida. A equação de demanda é descrita como:

$$
D_{t}=\frac{\alpha \cdot e^{\lambda\left(t+q_{M A X_{t}}\right)}}{\bar{p}_{t}{ }^{\varepsilon}}
$$

em que, ${ }^{D_{t}}$ é a demanda total do mercado, $\alpha$ é o tamanho inicial do mercado, $\lambda$ é a taxa de crescimento da demanda do mercado, $\bar{p}_{t}$ é o preço médio do mercado e $\varepsilon$ representa a elasticidade-preço do mercado. A variável ${ }^{q_{M A X}}$ representa a qualidade máxima obtida no setor, isto é, a maior qualidade alcançada entre as firmas do setor ${ }^{3}$.

(1) No modelo aqui proposto, o ajuste da demanda à inovação de produto ocorre com defasagem de 4 períodos de produção.

(2) $\bar{p}_{t}$ é a média harmônica da razão entre o market-share $\left(\mathrm{s}_{\mathrm{i}, \mathrm{t}}\right)$ e o preço praticado por cada firma $\mathrm{p}_{\mathrm{i}, \mathrm{t}}$ :

$\bar{p}_{t}=\frac{1}{\sum\left(\frac{s_{i, t}}{p_{i, t}}\right)}$.

3 Nas simulações foram adotados: $\alpha=60.000 ; \gamma=0,01 ; \bar{p}_{t}=100$ e $\varepsilon=1$. 


\subsubsection{Decisões de produção}

As decisões de produção são baseadas na determinação da produção programada, a qual depende das seguintes variáveis: (a) vendas previstas; (b) estoques; (c) encomendas efetivas. A produção programada é determinada por:

$$
\begin{gathered}
x_{i, t}^{*}=x_{i, t}^{e}(1+\sigma)-x_{i, t-1}^{s} \\
0 \leq x_{i, t}^{*} \leq \bar{x}_{i, t},
\end{gathered}
$$

onde $\sigma$ é determinado exogenamente ${ }^{4}$. A produção no início do período t é representada por $x_{i, t}^{*}$ e visa atender os seguintes objetivos: (a) as vendas previstas ou esperadas $x_{i, t}^{e}$ para o final do período de produção; (b) a manutenção do estoque $x_{i, t}^{s}$. O nível do estoque é determinado como uma proporção fixa $\sigma$ das vendas, utilizando as vendas previstas como proxy das vendas, dado que estas ainda não são conhecidas. O nível máximo de produção é dado pela capacidade produtiva instalada $\bar{x}_{i, t}$, medida em unidades de produção.

As vendas previstas são definidas por:

$$
x_{i, t}^{e}=e_{i, t-1}+\gamma\left(e_{i, t-1}-e_{i, t-2}\right)
$$

onde $\gamma$ é definido exogenamente 5 .

Os autores supõem que a formação de expectativas da firma quanto às vendas segue a regra de expectativas extrapolativas, a partir das encomendas efetivas $e_{i, t-1}$, definidas como:

$$
e_{i, t}=s_{i, t} e_{t}
$$

em que $e_{t}$ e $s_{i, t}$ representam, respectivamente, a demanda total do mercado e o market share da firma. abaixo:

Os estoques de produtos acabados são estabelecidos conforme equação

$$
x_{i, t}^{s}=x_{i, t}^{*}+x_{i, t-1}^{s}-x_{i, t}
$$

sendo $x_{i, t}$ as vendas.

(4) No modelo de Possas, Koblitz et al. (2001), fixou-se $\boldsymbol{\sigma}=0,1$, isto é, as empresas estão dispostas a estocar $10 \%$ das vendas como margem de segurança.

(5) No modelo supracitado, $\gamma=1$. 
As encomendas efetivas (equação 4) dependem de um fator exógeno (demanda total do mercado) e um fator endógeno (market share). O market share $s_{i, t}$ é determinado pela replicator dynamic equation e definido como função de um índice de competitividade ${ }^{E}$, com base no preço e no atraso de entrega (a seguir, equação 3). A competitividade da firma é dada por:

$$
E_{i, t}=\frac{q_{i, t}^{\varepsilon_{q}}}{p_{i, t}^{\varepsilon_{p}} \cdot d d_{i, t}^{\varepsilon_{d d}}}
$$

em que $p_{i}$ é o preço, ${ }^{d d_{i}}$ é o atraso de entrega da firma $i,{ }^{q}$ representa a qualidade

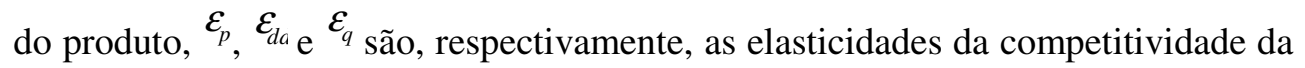
firma em relação ao preço, ao atraso de entrega ${ }^{6}$ e à qualidade do produto.

A partir da definição dos índices de competitividade é possível determinar $s_{i, t}$ como função da razão entre a competitividade da firma e a competitividade média do mercado:

$$
s_{i, t}=s_{i, t-1}\left[1+\mu\left(\frac{E_{i, t}}{\bar{E}_{t}}-1\right)\right]
$$

onde

$$
0 \leq \mu \leq 1 \quad \text { e } \quad \bar{E}_{t}=\sum_{i=1}^{n} E_{i, t} s_{i, t-1} .
$$

A noção de competitividade adotada é compatível com a observação de Silverberg (1987), segundo a qual são as alterações relativas de preços, e não variações absolutas, que levam o consumidor a desviar suas encomendas de um fornecedor para outro.

2.2 Bloco 1b: decisões de preço

A equação de preços é consistente com a replicator equation apresentada em Silverberg, Dosi e Orsenigo (1988) e com a equação de preços utilizada em Kalecki (1954, cap. 1) para a análise do "grau de monopólio":

$$
\frac{p_{i, t}-p_{i, t-1}}{p_{i, t-1}}=\theta\left(\frac{p_{i, t}^{d}-p_{i, t-1}}{p_{i, t-1}}\right)+(1-\theta)\left(\frac{E_{i, t-1}}{\bar{E}_{t-1}}-1\right)
$$

O parâmetro (atualizável) $\theta$, utilizado no cálculo do mark-up desejado e do preço, define a agressividade competitiva da empresa em preço, e é atualizado por:

(6) O índice de atraso de entrega, acompanhando Silverberg et al. (1988), é determinado por $d d_{i, t}=\frac{e_{i, t-1}}{x_{i, t-1}}$. 
Um modelo setorial baseado na abordagem kaleckiana da distribuição setorial funcional da renda...

$$
\theta_{i, t}=\theta_{i, t-1}\left[1+\varphi\left(\frac{\bar{s}_{i, t-1}-s_{i, t}^{d}}{s_{i, t}^{d}}\right)\right]
$$

em que $\bar{S}_{i, t-1}$ e $s_{i, t}^{d}$ representam, respectivamente, o market share médio (dos últimos 8 períodos) da firma i, com 1 período de defasagem, e o market share desejado,

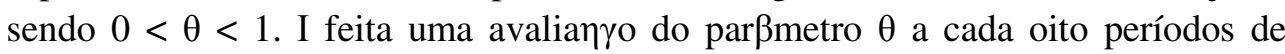
produção a partir da comparação entre o market share médio defasado em um período e o market share desejado da firma i. Quando $\bar{s}_{i, t-1}>s_{i, t}^{d}$, haverá um incremento da variável $\theta$, caso contrário, ela será reduzida. O parâmetro $\varphi$, por sua vez, define o peso da diferença relativa entre o market share médio defasado e o market share desejado na atualização do valor da variável $\theta$. No presente modelo, $\varphi$ $=1$.

A especificação da equação (8) acima é simplificada da seguinte forma: o preço da firma é formado por uma média ponderada entre o preço desejado e o preço médio do setor. Esta ideia pode ser melhor compreendida rearranjando os termos da equação de preços, deixando de lado o atraso de entrega, considerando $\varepsilon_{\mathrm{p}}=1 \mathrm{e}$ substituindo a equação de competitividade original ${ }^{7}$ na equação de preços:

$$
p_{i, t}=\theta p_{i, t}^{d}+(1-\theta) \bar{p}_{t-1}
$$

ou

$$
k_{i}=\theta k_{i}^{d}+(1-\theta) \frac{\bar{p}_{t-1}}{u_{i, t}}
$$

O preço $p_{i}^{d}=k_{i}^{d} u_{i}$ na equação (6) representa o preço desejado da firma, quando esta aplica o mark-up desejado, ${ }_{i}^{d}$, sobre os custos variáveis médios $u_{t, t}{ }^{8} \mathrm{Na}$ equação (11) o mark-up efetivo $\left(k_{i}\right)$ é resultado de uma solução de conciliação entre o mark-up desejado, ou mark-up estratégico de longo prazo, e as condições vigentes no curto prazo e corresponde ao preço efetivo $\left(p_{i}\right)$ a cada período. Esta equação equivale à utilizada por Kalecki (1954, cap. 1), que pode ser interpretada como uma extensão do princípio do custo total em condições de oligopólio diferenciado, pois ao formar seu preço a firma considera, além de seu nível de aspiração desejado de longo prazo ou mark-up desejado $\left(k^{d}\right)$, as condições vigentes no mercado no curto prazo, isto é, o preço praticado pelas demais firmas.

(7) A equação de competitividade, originalmente proposta em Siverberg et al. (1988) e incorporaqla em Possas, Koblitz et al. (2001), sem considerar os efeitos das inovações de produto, era definida como: $\frac{E_{i, t}}{=} \frac{\varepsilon_{i, t}^{\varepsilon_{p}} d d_{i, t}^{\varepsilon_{d d}}}{p}$.

(8) Para determinar o mark-up desejado a firma considera, além de seu preço desejado, o comportamento do mercado, com base na diferença entre sua competitividade e a competitividade média. A equação do mark-up desejado será definida posteriormente. 
A introdução de inovações de produto possibilita uma ampliação mais acentuada do mark-up desejado, pois a competitividade deixa de depender exclusivamente do preço. Dessa forma, o mark-up desejado será influenciado pela variação da qualidade do produto, que aumenta a competitividade da firma, e reajustado a cada oito períodos de produção de acordo com a expressão abaixo:

$$
\left.k_{i, t}^{d}=k_{i, t-1}^{*}+\chi \cdot \bar{k}_{i, t-1}^{p} \cdot\left(1+\varphi \cdot\left(\frac{E_{i, t-1}-\bar{E}_{t-1}}{\bar{E}_{t-1}}\right)\right)-k_{i, t-1}^{d}\right]
$$

De acordo com a equação acima, o mark-up desejado é formado, em primeiro lugar, pela variável $k_{i, t-1}^{*}$, que estabelece o mark-up que a firma utiliza para calcular seu preço desejado, definida respeitando as condições abaixo:

(i) Se $k_{i, t}^{d}<k_{i, t-1}^{d}$ então $k_{i, t}^{*}=k_{i, t-1}^{d}$.

Neste caso, sempre que o mark-up desejado do período atual for inferior ao mark-up desejado do período anterior, a variável $k_{i, t}^{*}$ assumirá este último valor.

(ii) $\mathrm{Se} k_{i, t}^{d} \geq k_{i, t-1}^{d}$ e $\frac{u_{i, t}-u_{i, t-1}}{u_{i, t-1}}<0$ então $k_{i, t}^{*}=\min \left(k_{i, t}^{d}, k_{i, t}^{\max }\right)$.

A variável assumirá no período o menor valor entre o mark-up desejado e o valor máximo que o mark-up pode assumir de forma a manter o preço desejado constante $\left({ }^{k_{i, t}^{\max }}\right)^{9}$, o que ocorrerá sempre que o mark-up desejado do período atual for maior ou igual ao mark-up desejado do período anterior e ocorrer uma redução do custo variável unitário entre os períodos. Dessa forma, é possível aumentar o mark-up desejado em função da redução dos custos variáveis unitários, mantendo constante o preço desejado.

(iii) $\mathrm{Se} k_{i, t}^{d} \geq k_{i, t-1}^{d}$ e $\frac{u_{i, t}-u_{i, t-1}}{u_{i, t-1}}>0$ então $k_{i, t}^{*}=k_{i, t-1}^{*}$.

Neste último caso, ainda que o mark-up desejado do período atual seja maior ou igual ao mark-up desejado do período anterior, o aumento do custo variável unitário impede qualquer reajuste da variável $k_{i, t}^{*}$, mantendo seu valor atual igual ao valor assumido no passado. Em tais circunstâncias, o preço desejado aumentará na mesma proporção do aumento do custo variável unitário.

(9) A variável $k_{i, t}^{\max e ́ ~ c a l c u l a d a ~ a ~ p a r t i r ~ d o ~ m a r k-u p ~ d o ~ p e r i ́ o d o ~ a n t e r i o r ~ e ~ d a ~ v a r i a c ̧ a ̃ o ~ d o ~ c u s t o ~ v a r i a ́ v e l ~}$ unitário: $k_{i, t}^{\max }=k_{i, t-1}^{*}\left(1+\frac{u_{i, t-1}-u_{i, t}}{u_{i, t}}\right)$. 
A outra parte do mark-up desejado será determinada pela diferença entre o mark-up potencial médio do período anterior ajustado pela variação da competitividade $\left({ }^{p_{i, t-1}^{*}}\right)^{10}$, e o mark-up desejado da firma no período anterior. Esta diferença é ponderada pelo parâmetro $\chi$ o qual, conceitualmente, indica a importância atribuída pela firma ao comportamento do mercado, isto é, à diferença entre $\bar{k}_{i, t-1}^{p^{*}} \mathrm{e}^{k_{i, t-1}^{d}}$, na determinação de seu mark-up desejado.

A regra de determinação do mark-up desejado revela o caráter estratégico desta variável para a firma. Como as alterações no mark-up desejado dependem da posição competitiva da firma no seu mercado de atuação, a ampliação desta variável está condicionada à capacidade de aumentar seu market share, por meio da introdução de inovações de processo redutoras de custo e/ou inovações de produto que permitam a obtenção de um preço 'prêmio'. A prática de mark-ups que crescem a taxas elevadas, gerando trajetórias explosivas, seria compatível apenas com situações de elevada e crescente concentração do mercado. No entanto, como o modelo prevê entrada e saída de firmas e oportunidade tecnológica para imitação, a possibilidade de concentração total no mercado é baixa. Dessa forma, a ampliação do mark-up sempre estará condicionada ao posicionamento da firma no seu mercado de atuação.

\subsection{Bloco 2 - Determinação das decisões de investimento}

A decisão de investir é tomada com base em dois componentes: (a) ajuste do grau de utilização de capacidade; (b) modernização tecnológica.

(10) O mark-up potencial médio da firma, $\bar{k}_{i}^{p}$, é obtido a partir do mark-up potencial da firma nos últimos oito períodos: ${ }_{k i, t}^{p}=\frac{k_{i, t}^{p}+k_{i, t-1}^{p}+k_{i, t-2}^{p}+k_{i, t-3}^{p}+\ldots+k_{i, t-7}^{p}}{8}$, em que, $k_{i, t}^{p}=\frac{\bar{p}_{t}}{u_{i, t}} \cdot$ O mark-up potencial $\left(k_{i, t}^{p}\right)$ representa a margem do preço médio do mercado $\left(\bar{p}_{t}\right)$ sobre o custo variável unitário da firma $\left(u_{i, t}\right)$. Este custo, $u_{i, t}$, é a soma do custo unitário com matéria-prima e outros insumos, $m_{\uparrow}$, e o custo unitário com mão de obra, o qual depende da taxa de salário nominal, $w_{i, t}$, e da produtividade média da firma, $\bar{\pi}_{i, t}$, de forma que: $u_{i, t}=m_{i}+\frac{w_{i, t}}{\bar{\pi}_{i, t}} \cdot m_{i}$ é definido como parâmetro $\left(m_{i}=40\right)$, enquanto as variáveis $w_{i, t}$ e $\bar{\pi}_{i, t}$ possuem, respectivamente, as condições iniciais 40 e 1 . Por sua vez, o mark-up potencial médio do período anterior ajustado pela variação da competitividade da firma $\left(E_{i, t}\right)$ em relação à média do setor $\left(\bar{E}_{t}\right)$, ponderada pelo parâmetro $\varphi$, é definido por: $\bar{k}^{-p_{i, t-1}^{*}}={ }_{k i, t-1}^{-p}\left(1+\varphi\left(\frac{E_{i, t-1}-\bar{E} t-1}{\bar{E} t-1}\right)\right)$. 


\section{Ajuste do grau de utilização da capacidade}

O período de investimento ( $\mathrm{T}$ ) é composto por quatro períodos de produção. Os equipamentos encomendados ao final do período de investimento corrente estarão disponíveis apenas no segundo período de investimento à frente $(\mathrm{T}+2)$. A previsão de encomendas (vendas potenciais) para o período $\mathrm{T}+2, x_{i, T+2}^{e}$, é feita por extrapolação das encomendas médias dos períodos de investimentos anteriores.

\section{Modernização tecnológica}

A decisão de investimento em modernização tecnológica é feita a partir da comparação entre os custos de reposição dos equipamentos antigos e os ganhos de redução de custos pelo uso de uma nova safra de bem de capital ao longo de um período de payback (pb), no qual se espera obter o retorno para o investimento em modernização:

$$
\frac{p_{F, t}^{b k}}{w\left(\frac{1}{\pi_{i, j, t}}-\frac{1}{\pi_{i, t}^{F}}\right)} \leq p b
$$

Na equação acima $p_{F, t}^{b k}$ é o preço do novo bem de capital, $\pi_{i, j, t}$ é a produtividade corrente do bem de capital da safra antiga e $\pi_{i, t}^{F}$ a produtividade do bem de capital da fronteira tecnológica.

\subsection{Bloco 3 - Procedimentos de busca tecnológica}

Seguindo Nelson e Winter (1982), na determinação dos procedimentos de busca tecnológica as firmas são divididas em imitativas e inovativas. As novas tecnologias são adquiridas via estratégia de imitação das inovações introduzidas por outras firmas ou via estratégia de inovação, em que a própria firma introduz a inovação primária. O modelo é construído sob o pressuposto de que a difusão do sucesso inovativo ou imitativo dentro da firma depende dos investimentos em capital fixo, isto é, a tecnologia é "capital embodied". A hipótese do modelo é que a introdução de avanços tecnológicos em cada setor seja feita basicamente por meio de aquisições de bens de capital, porém considera-se que a atividade de $\mathrm{P} \& \mathrm{D}$ interna das firmas é crucial para o projeto, operação adequada e aperfeiçoamento tecnológico dos equipamentos adquiridos via aprendizado.

O modelo supõe que o estoque de capital fixo da firma é composto por equipamentos de diferentes produtividades, de forma que esta depende de quais 
desses bens são utilizados. Os efeitos do aprendizado são incorporados no modelo por meio das seguintes regras de comportamento, com base em Possas et al. (2001):

$$
S K I L L_{l, t}=1+B O N U S \times\left[1-\exp \left(-V_{-} S K I L L_{t} \times C Q_{i, t-1}\right)\right]
$$

onde:

SKILL $L_{i, t}$ é uma variável que representa o efeito do aprendizado da firma i sobre a produtividade a partir da produção acumulada $\left(C Q_{i, t}\right)$ de cada bem de capital;

BONUS é um parâmetro que mede o aumento máximo de produtividade alcançado por meio do efeito aprendizado ${ }^{11}$.

V_SKILL é um parâmetro que define a taxa de crescimento do efeito de aprendizado em função da produtividade acumulada ${ }^{12}$.

A vantagem competitiva associada ao uso de um equipamento mais produtivo é potencializada pelos ganhos de produtividade provenientes do efeito do aprendizado do tipo learning by doing, sendo estes totalmente incorporados pela firma. A existência deste efeito de aprendizagem tende a reforçar até certo ponto o sucesso das firmas inovadoras, em especial aquelas que realizam inovações de processo. Este efeito é comentado nas simulações apresentadas na próxima seção. No modelo de Possas et al. (2001), os efeitos de learning by doing são específicos a cada equipamento; quando este é substituído por outro mais produtivo a firma passa para uma nova "curva de aprendizado". Um pressuposto importante do modelo é que o aumento de produtividade, proveniente do processo de learning by doing, dentro de um mesmo equipamento tende progressivamente a se esgotar. Este efeito leva à necessidade de aquisição de novos equipamentos para manter os ganhos de produtividade no longo prazo, dando oportunidade às firmas que ficaram para trás realizarem o catching-up ou mesmo ultrapassarem as firmas líderes em tecnologia no modelo antigo.

Assume-se que a firma adquire o equipamento com maior produtividade, por imitação ou inovação, seguindo processos estocásticos em dois estágios:

a) Produtividade associada à imitação de processo

$1^{o}$ estágio: escolha da produtividade $\pi_{z, t}^{M}$ a imitar

$$
\pi_{z, t}^{M}=d_{m \max _{i, j}}\left(\pi_{i, j, z, t}^{0}\right)
$$

(11) No modelo BONUS $=0,15$.

(12) No modelo V_SKILL $=0,05$. 
onde $\pi_{i, j, z, t}^{0}$ é a produtividade do bem de capital $j$ da firma $i$ no setor $z$ (tecnologia da fronteira).

$2^{o}$ estágio: probabilidade de sucesso imitativo em processo $\left(d_{m}=1\right)$

$$
\operatorname{Pr}\left(d_{m}=1\right)=1-\exp \left(-\rho_{m, i} p_{i, t} x_{i, t} a_{m}\right)
$$

em que $d_{m}$ é uma variável aleatória com distribuição de Bernoulli, representando, respectivamente, sucesso ou fracasso do esforço imitativo, conforme $\mathrm{d}_{\mathrm{m}}=1$ e $\mathrm{d}_{\mathrm{m}}=0$. O parâmetro $\rho_{m, i}$ expressa quanto a firma gasta em P\&D imitativo como proporção da receita, e $a_{m}$ é um parâmetro exógeno de oportunidade tecnológica de sucesso imitativo $^{13}$.

b) Produtividade associada à inovação de processo

$1^{\circ}$ estágio: probabilidade de sucesso inovativo em processo

$$
\operatorname{Pr}\left(d_{n}=1\right)=1-\exp \left(-\rho_{n, t} \rho_{i, t} x_{i, t} a_{n}\right)
$$

onde analogamente $d_{n}$ é uma variável aleatória com distribuição de Bernoulli, $\rho_{n}$ é a proporção da receita gasta com $\mathrm{P} \& \mathrm{D}$ inovativo e $a_{n}$ é o parâmetro exógeno de oportunidade tecnológica de sucesso inovativo em processo. ${ }^{14}$

$$
d_{n}=1 \text { ) estágio: produtividade obtida pela inovação de processo (ocorre se }
$$

$$
\log \left(\pi_{i, t}^{N}\right) \sim \mathrm{N}\left(\mu ; \sigma^{2}\right)
$$

onde $\sigma$ é dado exogenamente.

A produtividade da nova tecnologia será dada por uma variável lognormal com valor esperado crescendo, por hipótese, a uma taxa exógena, devido ao pressuposto de regime "science based" ${ }^{15}$, em que o parâmetro $\mu$ equivale à oportunidade tecnológica para inovação de processo no setor.

A escolha tecnológica final definirá a produtividade da "fronteira" interna da firma $\left(\pi^{F}\right)$ :

$$
\pi_{i, t}^{F}=\max \left(\pi_{i, t-1}^{F} \pi_{i, t}^{N} \pi_{i, t}^{M}\right)
$$

\footnotetext{
(13) O parâmetro de oportunidade tecnológica de sucesso imitativo foi ajustado para gerar o valor esperado de dois sucessos imitativos no mercado por período de investimento, resultando no valor 0,00008 para o parâmetro.

(14) Idem à nota anterior. $\mathrm{O}$ parâmetro assume o valor 0,0002 .

(15) Nas simulações foi suposto $\mu=1+g^{\mu} t$ e $\sigma$ fixo. O parâmetro $g^{\mu}$ reflete a taxa de crescimento da produtividade latente, isto é, a taxa de crescimento da oportunidade tecnológica no setor.
} 
No caso da inovação de produto, o efeito positivo sobre a competitividade é captado pela introdução de diferenciais de qualidade do produto, a partir de gastos em inovação e imitação seguindo processos estocásticos em dois estágios, como aqueles descritos anteriormente. No caso da qualidade obtida por meio dos gastos em inovação de produto, aplica-se a mesma regra definida na equação (18). A diferença, neste caso, é que o parâmetro $\mu$ equivale à qualidade latente ou oportunidade tecnológica para inovação de produto e $\mathrm{g}^{\mu}$ corresponde ao ritmo de deslocamento da fronteira tecnológica dada pela taxa de crescimento do valor esperado do logaritmo da qualidade obtida com uma inovação bem-sucedida.

\subsection{Bloco 4 - Geração e distribuição da renda}

$\mathrm{O}$ avanço tecnológico, ao influenciar preço e mark-up, afeta a distribuição setorial funcional da renda. Esta ideia parte da proposta Kaleckiana de determinação da distribuição funcional da renda considerando as especificidades do processo de formação de preços.

Uma vez que os preços e salários, em mercados regidos por mark-up, são definidos no momento da decisão de produção ou pouco antes, é possível determinar o excedente unitário de cada firma subtraindo do preço o pagamento de impostos indiretos e custos unitários de salários e insumos.

$$
e x_{t}=\left(1-\tau^{i}\right) p_{t}-u_{t}
$$

em que, ex é o vetor dos excedentes brutos unitários das firmas, $\tau^{i}$ é o vetor formado pelas alíquotas de imposto indireto sobre as vendas ${ }^{16}, p_{t}$ e $u_{t}$ são respectivamente os vetores de preços e custos unitários. O excedente bruto total de cada firma é obtido multiplicando o excedente unitário pelas vendas determinadas ex post. A introdução de inovações de produto e de processo influencia o excedente bruto por meio dos vetores de preço e custos unitários. No primeiro caso, o progresso técnico permite que o aumento de qualidade do produto $\left(\mathrm{q}_{\mathrm{t}}\right)$ exerça impacto positivo sobre o preço e o excedente bruto, sem comprometer a competitividade da firma. No segundo caso, o aumento da produtividade do trabalho e a consequente redução dos custos variáveis, decorrente da inovação de processo, leva à redução de $u$ e $p$, o que permite aumento de competitividade e expansão do market share, enquanto o efeito sobre o mark-up depende da magnitude da redução do preço frente à queda do custo variável de produção.

A equação de salário é definida por:

$$
w_{j, t}=w_{j, t-1}\left[1+\gamma\left(\frac{\bar{\pi}_{j, t-1}-\bar{\pi}_{j, t-5}}{\bar{\pi}_{j, t-5}}\right)\right],
$$

(16) No modelo, supõe-se um imposto indireto sobre as vendas de $10 \%$. 
onde $\gamma$ é dado exogenamente e determina a parcela do aumento de produtividade devido ao progresso técnico que é incorporada no salário.

\section{Resultados}

As simulações serão apresentadas nas seguintes variáveis: (1) market share; (2) excedente bruto; (3) salários; (4) participação dos salários na renda no nível da firma; (5) participação dos salários na renda setorial; (6) concentração de mercado medida pelo índice Inverso de Hirschman-Herfindahl.

Os resultados a seguir têm o objetivo de apresentar os tipos de trajetórias geradas pelo modelo para as variáveis escolhidas acima ${ }^{17}$. As simulações foram realizadas comparando três tipos de setores estilizados: (i) setor em condiçõespadrão, com inovação de processo e sem inovação de produto; (ii) setor intensivo em inovação de produto; (iii) setor intensivo em inovação de processo. Neste modelo, as firmas diferem segundo os seguintes aspectos: (1) escolha da estratégia de preços, definida em termos do peso atribuído ao mark-up desejado (variável $\theta$ da equação de preços) vis-à-vis o preço médio do mercado; (2) estratégia de busca tecnológica intensiva em inovação (ou imitação) de produto ou inovação (ou imitação) de processo, sendo definida com base na parcela da receita gasta em P\&D. As firmas estão divididas entre inovadoras fortes (4\% da receita gasta em P\&D inovativo e $2 \%$ destinados à imitação), inovadoras fracas ( $2 \%$ da receita gasta em P\&D inovativo e $4 \%$ destinado à imitação) e imitadoras estritas (4\% da receita gasta em P\&D imitativo). No caso dos setores (ii) e (iii), a parcela da receita gasta em P\&D para inovações de processo e inovações de produto determina se o setor é intensivo em inovação de processo ou em inovação de produto.

\subsection{Resultados das simulações nas condições-padrão}

As simulações apresentadas a seguir correspondem às "condições-padrão", pois representam as condições mais típicas para os parâmetros e condições iniciais. Estas simulações têm o objetivo de apresentar o funcionamento básico do modelo e as trajetórias por ele geradas. Neste caso, as simulações supõem um setor que não realiza inovações de produto; a elasticidade-preço da competitividade é unitária; e o

(17) O software utilizado para obter os resultados das simulações foi o Laboratory for Simulation Development (LSD). Os resultados apresentados em cada uma das simulações foram comparados com os resultados de dez rodadas de simulações, utilizando dez sementes aleatórias distintas. Não foram identificados resultados substancialmente diferentes entre cada uma das rodadas de simulação utilizando sementes aleatórias diferentes. A utilização de várias rodadas com sementes aleatórias distintas tem o objetivo de testar a validade do modelo, mostrando que os resultados obtidos não são fruto de aleatoriedade. No caso das variáveis agregadas no nível setorial - (a) Distribuição setorial funcional da renda; (b) Índice inverso de Hirschman-Herfindahl - os resultados apresentados correspondem a valores médios, a partir das diferentes rodadas supracitadas. 
repasse dos ganhos de produtividade para os preços, expresso pelo parâmetro $\gamma$, não é integral $(\gamma=0,75)$.

\section{Setor com inovação de processo e sem inovação de produto}

A escolha dos valores iniciais de variáveis e parâmetros específicos tem o propósito de representar o comportamento de um setor cuja estratégia tecnológica reside apenas na introdução de inovações de processo. Com a finalidade de comparar as trajetórias obtidas em diferentes configurações de variáveis e parâmetros, as condições iniciais e parâmetros a seguir representam um setor em condições-padrão.

As variáveis em que as simulações são apresentadas, delimitadas no tópico anterior, são analisadas primeiramente em um setor sem inovação de produto, para que seja possível verificar os impactos da inovação de produto no modelo. As simulações a seguir partem da premissa de que um oligopólio tecnologicamente dinâmico tenderá a competir em preço, mas evitando a queda do mark-up das empresas inovadoras, como resultado das inovações de processo, sem acarretar guerras de preços.

As simulações foram feitas considerando um setor com oito firmas e com as seguintes condições iniciais:

Tabela 1

Condições iniciais - Setor em condições-padrão (sem inovação de produto)

\begin{tabular}{|c|c|c|c|c|c|c|c|c|}
\hline \multicolumn{9}{|c|}{ Mercado } \\
\hline Oportunidade tecnológica para inovação de processo & 0,005 & & & & & & & \\
\hline Velocidade do aprendizado & 0,025 & & & & & & & \\
\hline Oportunidade tecnológica para inovação de produto & 0,00 & & & & & & & \\
\hline Elasticidade-preço da competitividade & 1,00 & & & & & & & \\
\hline Elasticidade-qualidade da competitividade & 0,00 & & & & & & & \\
\hline Firma & F1 & F2 & F3 & F4 & F5 & F6 & F7 & F8 \\
\hline Parcela da receita gasta com inovação de processo & 0,04 & 0,04 & 0,04 & 0,02 & 0,02 & 0,00 & 0,00 & 0,00 \\
\hline Parcela da receita gasta com imitação de processo & 0,02 & 0,02 & 0,02 & 0,04 & 0,04 & 0,04 & 0,04 & 0,04 \\
\hline Parcela da receita gasta com inovação de produto & 0,00 & 0,00 & 0,00 & 0,00 & 0,00 & 0,00 & 0,00 & 0,00 \\
\hline Parcela da receita gasta com imitação de produto & 0,00 & 0,00 & 0,00 & 0,00 & 0,00 & 0,00 & 0,00 & 0,00 \\
\hline Parâmetro $\gamma$ (equação de salário) & 0,75 & 0,75 & 0,75 & 0,75 & 0,75 & 0,75 & 0,75 & 0,75 \\
\hline Variável $\Theta$ (equação de preço) & 0,70 & 0,70 & 0,70 & 0,60 & 0,60 & 0,30 & 0,30 & 0,30 \\
\hline
\end{tabular}

Os parâmetros de oportunidade tecnológica para inovação de processo e inovação de produto informam, respectivamente, o crescimento exógeno da produtividade correspondente à fronteira tecnológica (produtividade latente) e o crescimento exógeno da qualidade correspondente à fronteira tecnológica (qualidade latente). A variável $\theta$ da equação de preços (peso do mark-up desejado na formação do preço) revela a estratégia competitiva da firma em relação à escolha do preço praticado. Como as firmas mais inovadoras tendem a ser líderes de preço e firmas mais imitadoras tendem a ser seguidoras, o maior $\theta$ associado às firmas inovadoras indica que o mark-up desejado é mais relevante que o mark-up ao preço de mercado na determinação do preço destas firmas, e vice-versa. Firmas mais inovadoras, seja 
em processo ou produto, apostam no sucesso inovativo para redução de custos ou aumento de qualidade dos produtos, de maneira a aumentar sua margem de lucro.

Nesta simulação-padrão (Figura 1) não há grande variabilidade entre os market shares de empresas inovadoras e imitadoras, indicando que o efeito de aprendizado permite às imitadoras manter fatias de mercado próximas àquelas obtidas pelas inovadoras, o que justifica a baixa concentração de mercado, verificada pelo índice de concentração inverso de Hirschman-Herfindahl. Não há grande dispersão do excedente bruto entre as empresas e a tendência declinante da participação do salário na renda é bastante sutil; portanto, a inovação de processo, neste caso, não aumenta significativamente a participação do excedente bruto, em detrimento dos salários, na renda setorial.

Figura 1

Market share, excedente bruto, salário, distribuição funcional setorial da renda e concentração de mercado em um setor sem inovação de produto

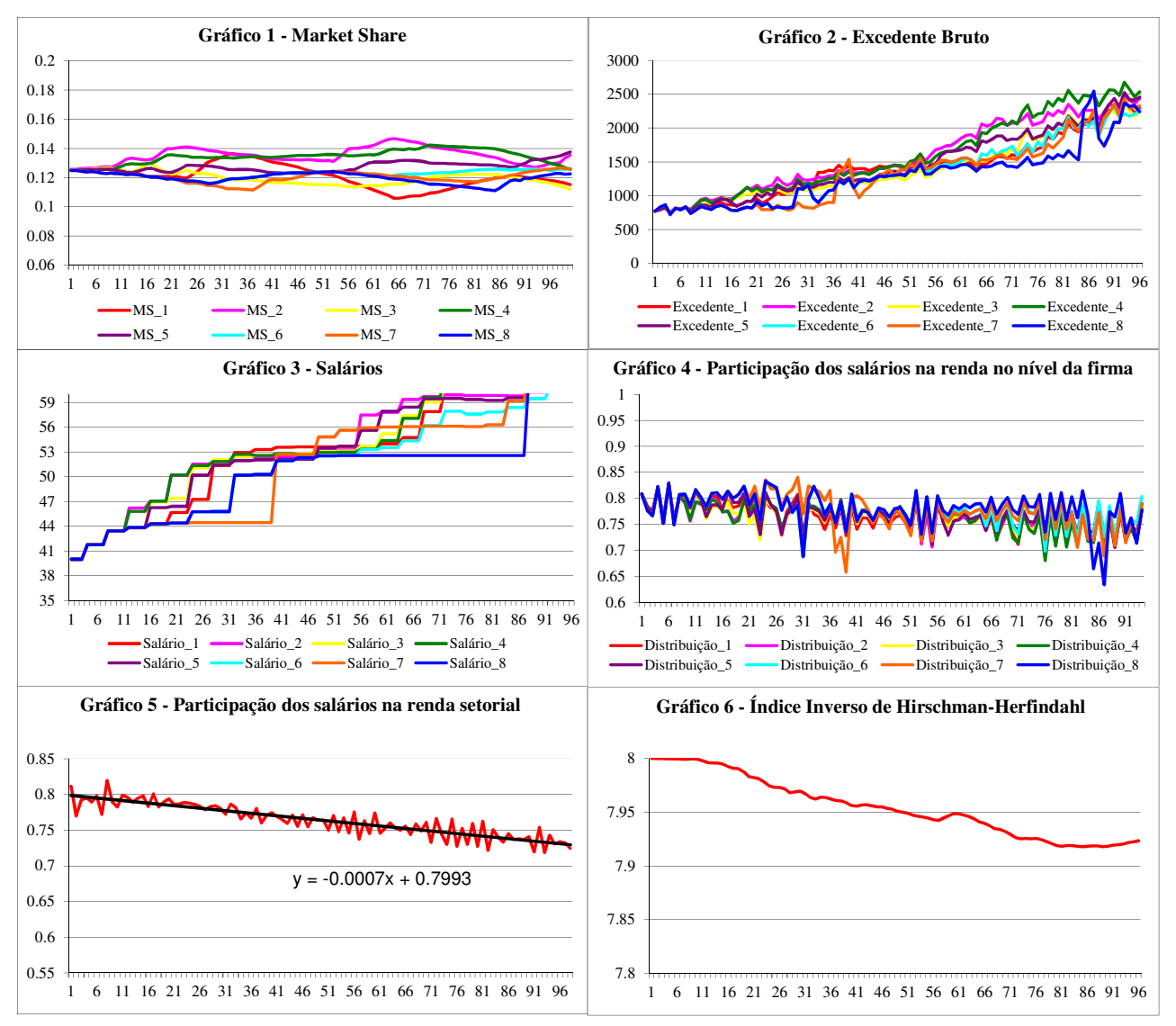




\subsection{Simulações específicas alterando variáveis estratégicas e parâmetros}

As seguintes simulações apresentam alterações na parcela da receita destinada a P\&D inovativo e P\&D imitativo em relação ao setor em condiçõespadrão. $\mathrm{O}$ gasto em $\mathrm{P} \& \mathrm{D}$ passa a ser dividido entre $\mathrm{P} \& \mathrm{D}$ destinado às inovações de produto e inovações de processo, bem como entre $\mathrm{P} \& \mathrm{D}$ destinado às imitações de produto e processo. Assim como nas simulações em condições-padrão, o setor é composto por três empresas inovadoras fortes, duas inovadoras fracas e três imitadoras. No entanto, o gasto em P\&D pode ser mais elevado em inovação de produto ou de processo. A alteração desta variável estratégica justifica mudança em parâmetros do ambiente de mercado, como o crescimento exógeno da produtividade e da qualidade na fronteira tecnológica, isto é, produtividade e qualidade latentes. Uma hipótese razoável é que em um setor intensivo em inovação de produto a qualidade latente cresça mais rápido que a produtividade latente e vice-versa para um setor intensivo em inovação de processo.

\subsubsection{Setor intensivo em inovação de produto}

As simulações a seguir representam um setor com firmas que realizam inovações e imitações de produto e processo, mas com maior intensidade dos gastos de P\&D em inovações de produto. Como a competição via inovação de produto é mais forte, foi atribuído um menor valor para a elasticidade-preço da competitividade em comparação à elasticidade-qualidade da competitividade. Da mesma forma, o parâmetro de oportunidade tecnológica para inovação de produto (i.e. o ritmo de deslocamento exógeno da fronteira tecnológica em termos do valor esperado da qualidade latente) é superior àquele para inovação de processo (idem para a produtividade latente). As condições iniciais estão definidas na Tabela 2:

Tabela 2

Condições iniciais - Setor intensivo em inovação de produto

\begin{tabular}{|c|c|c|c|c|c|c|c|c|}
\hline \multicolumn{9}{|c|}{ Mercado } \\
\hline Oportunidade tecnológica para inovação de processo & 0,002 & & & & & & & \\
\hline Velocidade do aprendizado & 0,025 & & & & & & & \\
\hline Oportunidade tecnológica para inovação de produto & 0,003 & & & & & & & \\
\hline Elasticidade-preço da competitividade & 0,50 & & & & & & & \\
\hline Elasticidade-qualidade da competitividade & 0,75 & & & & & & & \\
\hline Firma & F1 & F2 & F3 & F4 & F5 & F6 & F7 & F8 \\
\hline Parcela da receita gasta com inovação de processo & 0,01 & 0,01 & 0,01 & 0,01 & 0,01 & 0,00 & 0,00 & 0,00 \\
\hline Parcela da receita gasta com imitação de processo & 0,01 & 0,01 & 0,01 & 0,01 & 0,01 & 0,01 & 0,01 & 0,01 \\
\hline Parcela da receita gasta com inovação de produto & 0,03 & 0,03 & 0,03 & 0,01 & 0,01 & 0,00 & 0,00 & 0,00 \\
\hline Parcela da receita gasta com imitação de produto & 0,01 & 0,01 & 0,01 & 0,03 & 0,03 & 0,03 & 0,03 & 0,03 \\
\hline Parâmetro $\gamma$ (equação de salário) & 0,75 & 0,75 & 0,75 & 0,75 & 0,75 & 0,75 & 0,75 & 0,75 \\
\hline Variável $\Theta$ (equação de preço) & 0,70 & 0,70 & 0,70 & 0,60 & 0,60 & 0,30 & 0,30 & 0,30 \\
\hline
\end{tabular}

Na Figura 2 são apresentados os resultados das simulações. Observa-se um claro predomínio das inovadoras no aumento do market share e na geração de excedente bruto. $\mathrm{O}$ desempenho competitivo médio das inovadoras - especialmente as inovadoras "fracas" - supera o das imitadoras. No entanto, a estratégia de busca 
imitativa, associada aos efeitos do aprendizado, proporciona às firmas imitadoras sobrevivência e rentabilidade. Em comparação com a simulação padrão, ocorre concentração de mercado e queda da parcela dos salários na renda setorial. O aumento do parâmetro de oportunidade tecnológica para inovação de produto aumenta a concentração do mercado em favor das firmas inovadoras, conforme observado nos Gráficos 1 e 6 da Figura 2.

Figura 2

Market share, excedente bruto, salário, distribuição setorial funcional da renda e concentração de mercado em um setor intensivo em inovação de produto

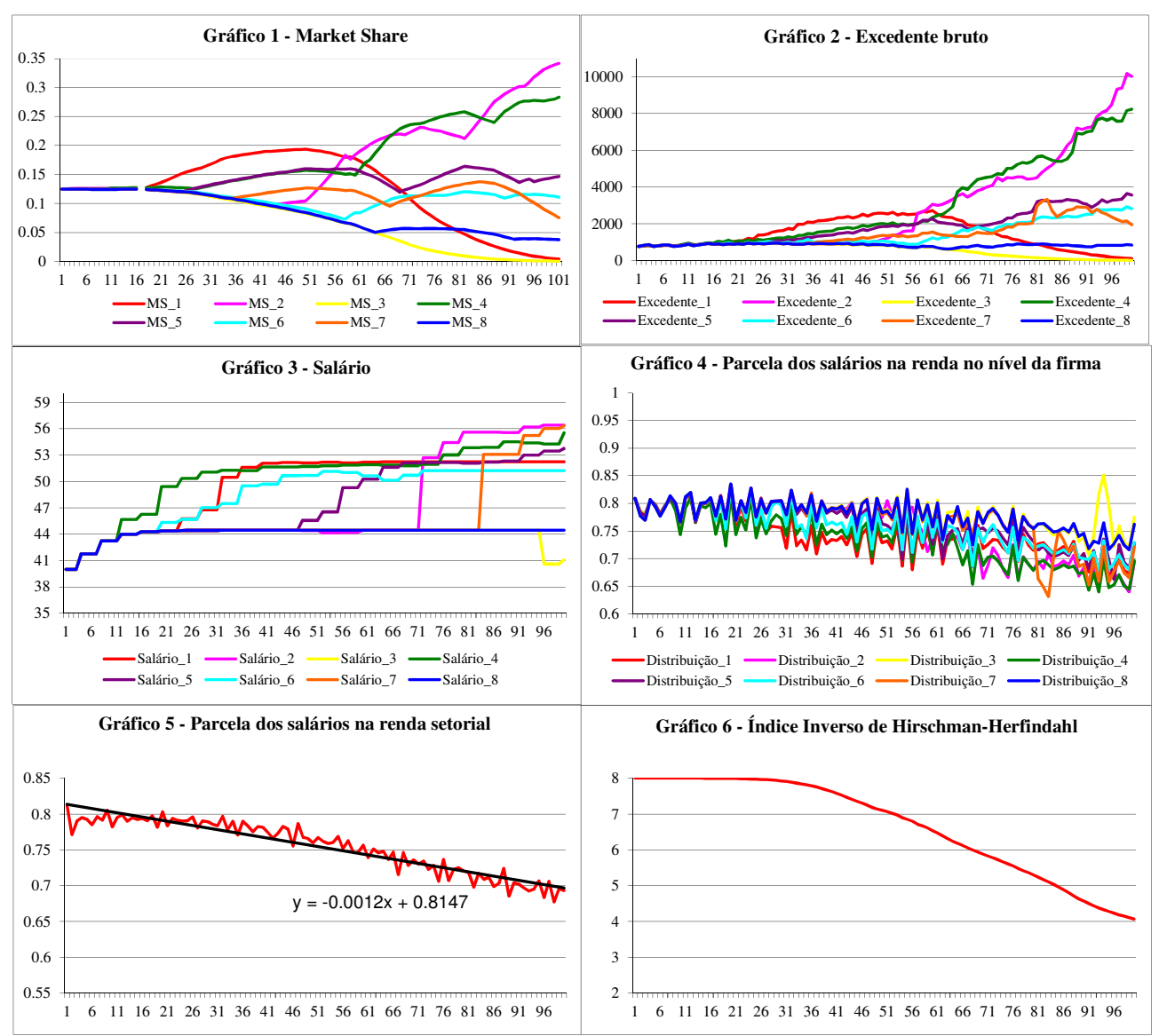

Em relação à apropriabilidade dos benefícios do progresso técnico, ainda que os salários aumentem ao longo do tempo, a distribuição da renda tende a privilegiar a participação do excedente bruto em detrimento dos salários não só em termos absolutos, como também relativamente à simulação nas condições-padrão, sem inovação de produto. Foi realizado um teste de comparação de médias em paired 
samples ${ }^{18}$ para saber se as médias dos resultados obtidos para um setor intensivo em inovação de produto são estatisticamente diferentes dos resultados obtidos nas simulações de um setor em condições padrão. $\mathrm{O}$ teste mostrou que as médias entre os dois cenários de simulação são estatisticamente diferentes, com confiança de $95 \%$ (estatística $\mathrm{t}=3.256)^{19}$. Dessa forma, o desvio da variável 'distribuição setorial funcional da renda' observado no caso de um setor com inovação de produto em relação ao setor em condições-padrão provém de mudanças nos parâmetros e condições iniciais. Isso sugere que quanto mais elevado o crescimento da qualidade latente (oportunidade tecnológica para inovação de produto), maior a possibilidade de as firmas inovadoras exercerem seu poder de mercado, em função da competição por maior qualidade dos produtos (Figura 3).

Neste setor, a estratégia de competição via diferenciação de produtos possibilita às empresas inovadoras, com exceções, exercerem seu poder de mercado por meio do aumento de preço, sem prejuízo de market share, como observado no Gráfico 1 da Figura 2.

Seguindo a tradição schumpeteriana, a inovação de produto opera como um elemento que revoluciona a estrutura industrial, de forma tal que a firma consegue influenciar o ambiente competitivo a seu favor, tornando possível o exercício de poder de mercado (Schumpeter, 1943, p. 110).

O ganho competitivo proveniente da estratégia de competição via introdução de inovações de produto é expresso no aumento do excedente bruto na renda setorial, Gráfico 2 da Figura 2, acompanhado por uma queda da participação dos salários na renda gerada, Gráfico 5.

Figura 3

Trajetória dos preços praticados pelas firmas em dois setores: setor sem inovação de produto e setor intensivo em inovação de produto

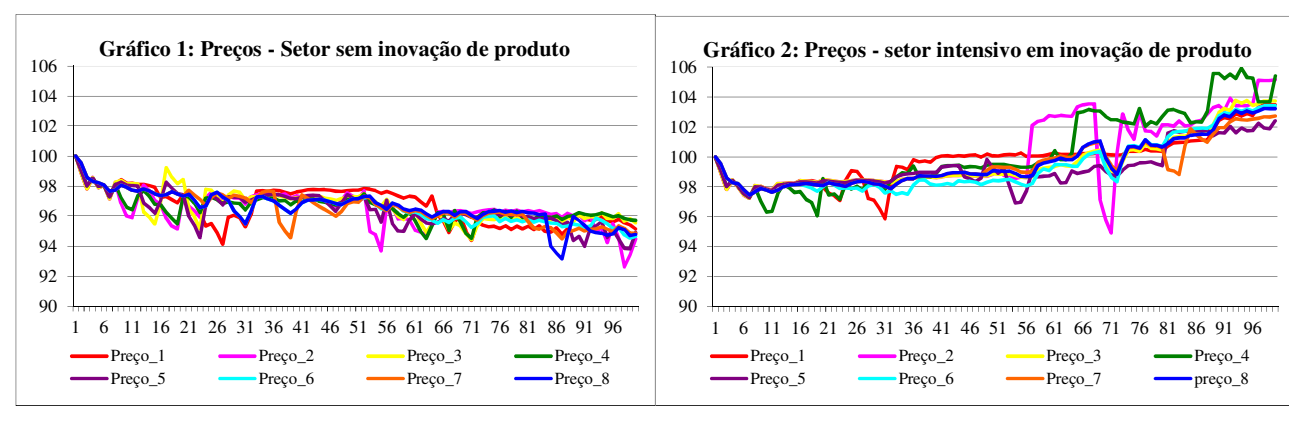

(18) Num estudo pareado tem-se duas amostras, sendo que cada observação da primeira amostra é pareada com uma observação da segunda amostra. Tal procedimento é aplicado quando há interesse em analisar medidas de um determinado objeto em duas situações, antes e depois da ocorrência de um evento. Como as duas observações pertencem ao mesmo objeto, não se espera que elas sejam estatisticamente independentes.

(19) Os resultados dos testes de comparação entre médias para amostras pareadas encontram-se no Anexo. 


\subsubsection{Setor intensivo em inovação de processo}

As simulações apresentadas a seguir representam um setor com empresas cujos gastos em P\&D são mais intensivos em inovações de processo. Neste contexto, foi atribuído maior valor ao parâmetro de elasticidade-preço da competitividade em comparação à elasticidade-qualidade da competitividade, bem como foi suposto um maior ritmo de crescimento das oportunidades tecnológicas para inovação de processo, em relação àquelas para inovação de produto, de forma simétrica ao caso anterior. As condições iniciais estão expressas na Tabela 3:

Tabela 3

Condições iniciais - Setor intensivo em inovação de processo

\begin{tabular}{|c|c|c|c|c|c|c|c|c|}
\hline \multicolumn{9}{|c|}{ Mercado } \\
\hline Oportunidade tecnológica para inovação de processo & 0,003 & & & & & & & \\
\hline Velocidade do aprendizado & 0,025 & & & & & & & \\
\hline Oportunidade tecnológica para inovação de produto & 0,002 & & & & & & & \\
\hline Elasticidade-preço da competitividade & 0,75 & & & & & & & \\
\hline Elasticidade-qualidade da competitividade & 0,50 & & & & & & & \\
\hline Firma & F1 & F2 & F3 & F4 & F5 & F6 & F7 & F8 \\
\hline Parcela da receita gasta com inovação de processo & 0,03 & 0,03 & 0,03 & 0,01 & 0,01 & 0,00 & 0,00 & 0,00 \\
\hline Parcela da receita gasta com imitação de processo & 0,01 & 0,01 & 0,01 & 0,03 & 0,03 & 0,03 & 0,03 & 0,03 \\
\hline Parcela da receita gasta com inovação de produto & 0,01 & 0,01 & 0,01 & 0,01 & 0,01 & 0,00 & 0,00 & 0,00 \\
\hline Parcela da receita gasta com imitação de produto & 0,01 & 0,01 & 0,01 & 0,01 & 0,01 & 0,01 & 0,01 & 0,01 \\
\hline Parâmetro $\gamma$ (equação de salário) & 0,75 & 0,75 & 0,75 & 0,75 & 0,75 & 0,75 & 0,75 & 0,75 \\
\hline Parâmetro ? (equação de preço) & 0,70 & 0,70 & 0,70 & 0,60 & 0,60 & 0,30 & 0,30 & 0,30 \\
\hline
\end{tabular}

As simulações apresentadas na Figura 4 mostram, assim como no caso anterior, que os efeitos do aprendizado tecnológico não são suficientes para aproximar as imitadoras estritas das inovadoras, promovendo um declínio dos market shares das imitadoras e uma tendência à concentração do mercado em favor das inovadoras. Em comparação com as condições-padrão, ainda que a parcela dos salários na renda setorial também tenha uma tendência declinante (Gráfico 5), os efeitos distributivos são sutis e não permitem afirmar que a condição intensiva em inovação de processo gere efeitos distributivos significativamente distintos. $\mathrm{O}$ teste de comparação de médias em amostras pareadas (Anexo) revelou que as médias entre os dois cenários de simulação (setor intensivo em inovação de processo e setor em condições padrão) não são estatisticamente diferentes, com confiança de $95 \%$ (estatística t $=0.097$ ). Por este motivo, não é possível argumentar que o aumento da oportunidade tecnológica para inovação de processo seja responsável por desvios distributivos relevantes. 
Um modelo setorial baseado na abordagem kaleckiana da distribuição setorial funcional da renda...

Figura 4

Market share, excedente bruto, salário, distribuição setorial funcional da renda e concentração de mercado em um setor intensivo em inovação de processo.

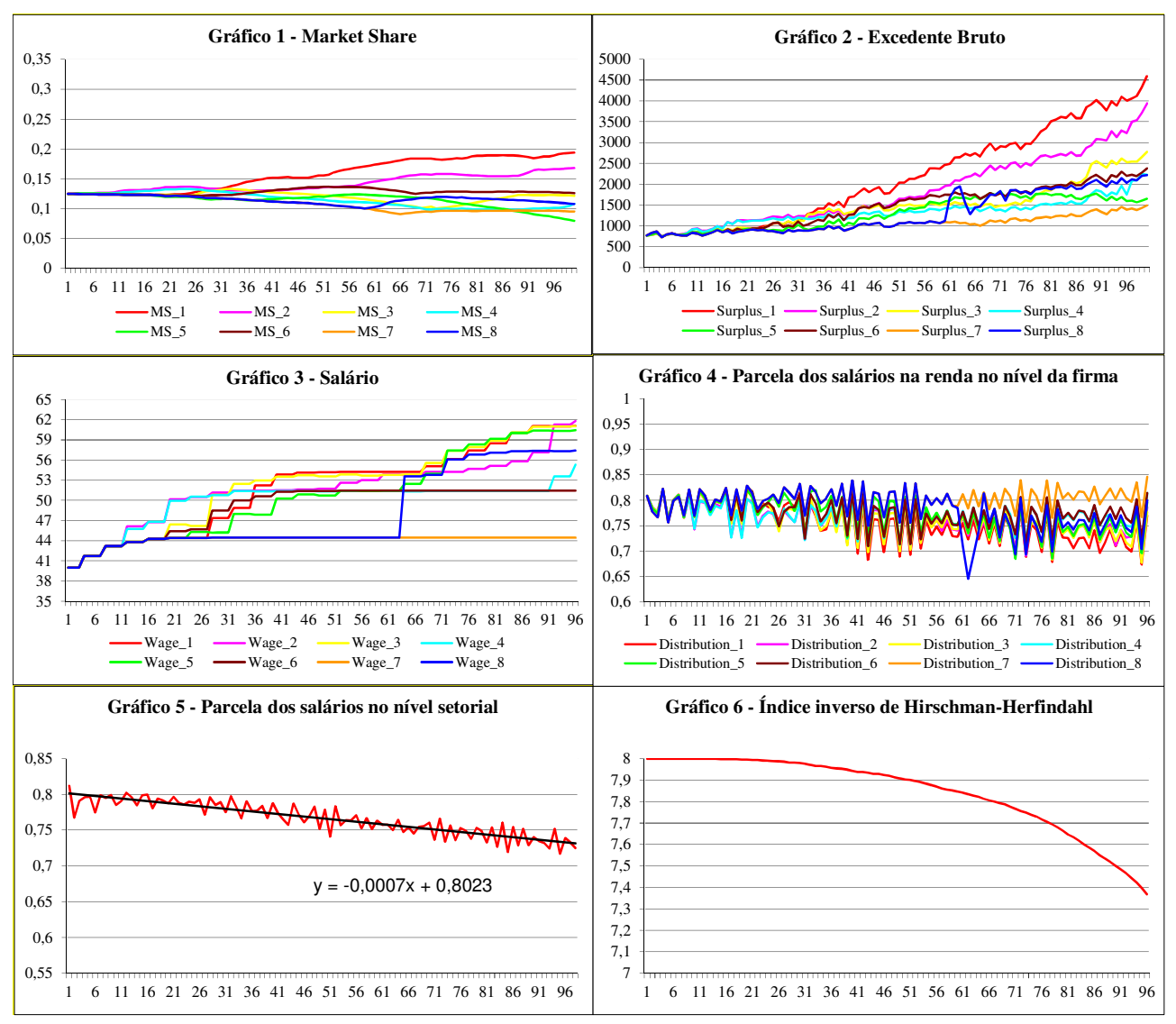

\subsection{Simulações envolvendo alteração de parâmetros do ambiente tecnológico}

Nas simulações apresentadas a seguir os parâmetros de oportunidade tecnológica para inovação de produto e inovação de processo foram alterados, em relação aos valores adotados nas duas situações anteriores (subseções 3.2.1 3.2.2). O objetivo das simulações apresentadas nesta seção é verificar se aumentos relativos nos parâmetros de oportunidade tecnológica geram efeitos distributivos importantes. Estas alterações são feitas de forma a aumentar a diferença entre os ritmos de crescimento da produtividade e qualidade latentes. A princípio, um aumento do crescimento da qualidade latente em relação à produtividade latente, por exemplo, beneficiaria as firmas inovadoras em produto. No entanto, a existência de oportunidade tecnológica para imitação, seja de produto ou de processo, faz com que algum efeito de aprendizado possa surgir, permitindo que as firmas imitadoras 
possam seguir as firmas inovadoras e, dessa forma, amenizar os benefícios das inovadoras, evitando grande divergência entre seus market shares e a tendência à concentração. Porém, as simulações mostram que o aprendizado, ao menos com os parâmetros adotados, não é suficiente para compensar a desvantagem das empresas imitadoras, observando-se o reforço da posição das firmas inovadoras e uma tendência à concentração.

\subsubsection{Setor intensivo em inovação de produto com alteração do parâmetro de oportunidade tecnológica}

Os resultados das simulações (Figura 5) mostram que o aumento do parâmetro de oportunidade tecnológica para inovação de produto, com redução daquele para inovação de processo, além de beneficiar as firmas inovadoras, ameniza os efeitos de aprendizado, determinados pela existência de oportunidade tecnológica para imitação de produto, responsáveis pela sobrevivência e rentabilidade das firmas imitadoras. O teste de comparação de médias para amostras pareadas mostrou que os resultados obtidos entre as simulações do setor intensivo em inovação de produto, com alteração no parâmetro de oportunidade tecnológica, e aquelas para o setor intensivo em inovação de produto, sem alterações ambientais, são estatisticamente diferentes - estatística $t=8.102$ (Anexo). Portanto, $o$ teste corrobora a conclusão de que o aumento da qualidade latente em relação à produtividade latente altera a distribuição de renda, desfavorecendo a participação dos salários na renda setorial.

Há uma tendência de declínio do market share e da geração de excedente bruto das firmas imitadoras nos últimos períodos da simulação, levando à concentração do mercado em favor das inovadoras.

Tabela 4

Condições iniciais - Setor intensivo em inovação de produto

\begin{tabular}{|c|c|c|c|c|c|c|c|c|}
\hline \multicolumn{9}{|c|}{ Mercado } \\
\hline Oportunidade tecnológica para inovação de processo & 0,001 & & & & & & & \\
\hline Velocidade do aprendizado & 0,025 & & & & & & & \\
\hline Oportunidade tecnológica para inovação de produto & 0,004 & & & & & & & \\
\hline Elasticidade-preço da competitividade & 0,50 & & & & & & & \\
\hline Elasticidade-qualidade da competitividade & 0,75 & & & & & & & \\
\hline Firma & F1 & F2 & F3 & F4 & F5 & F6 & F7 & F8 \\
\hline Parcela da receita gasta com inovação de processo & 0,01 & 0,01 & 0,01 & 0,01 & 0,01 & 0,00 & 0,00 & 0,00 \\
\hline Parcela da receita gasta com imitação de processo & 0,01 & 0,01 & 0,01 & 0,01 & 0,01 & 0,01 & 0,01 & 0,01 \\
\hline Parcela da receita gasta com inovação de produto & 0,03 & 0,03 & 0,03 & 0,01 & 0,01 & 0,00 & 0,00 & 0,00 \\
\hline Parcela da receita gasta com imitação de produto & 0,01 & 0,01 & 0,01 & 0,03 & 0,03 & 0,03 & 0,03 & 0,03 \\
\hline Parâmetro $\gamma$ (equação de salário) & 0,75 & 0,75 & 0,75 & 0,75 & 0,75 & 0,75 & 0,75 & 0,75 \\
\hline Parâmetro $\Theta$ (equação de preço) & 0,70 & 0,70 & 0,70 & 0,60 & 0,60 & 0,30 & 0,30 & 0,30 \\
\hline
\end{tabular}

Enquanto a trajetória dos salários é mantida praticamente constante, o excedente bruto das firmas inovadoras é crescente, elevando a apropriação dos lucros e reduzindo a participação dos salários na renda setorial de forma algo mais acentuada que na estrutura anterior de parâmetros, conforme observado no Gráfico 
5 da Figura 5. Enquanto a dispersão entre os excedentes brutos das firmas inovadoras e imitadoras é alta, entre os salários destes dois grupos de firmas a dispersão é baixa.

Figura 5

Market share, excedente bruto, salário, distribuição setorial funcional da renda e concentração de mercado em um setor intensivo em inovação de produto

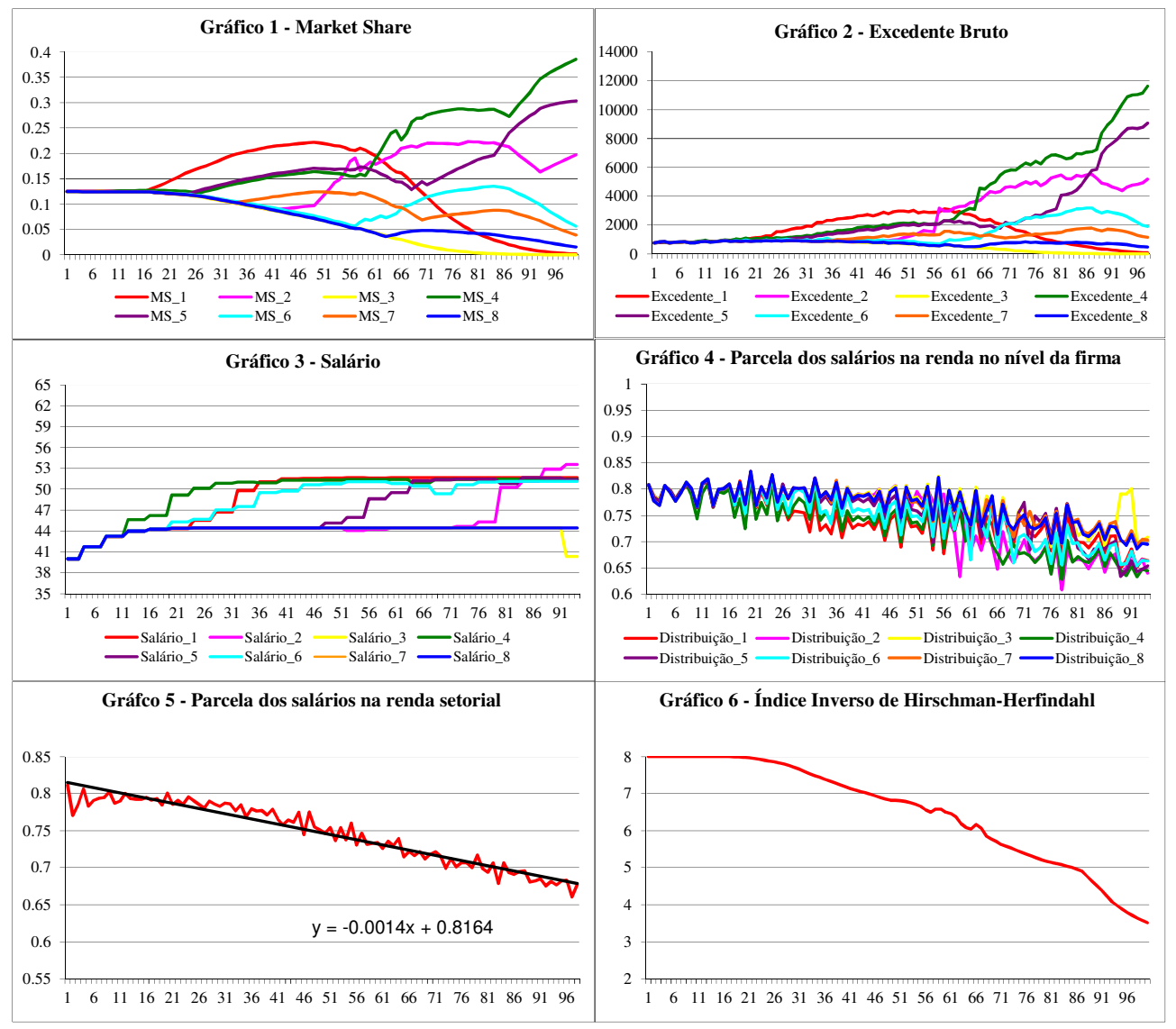

\subsubsection{Setor intensivo em inovação de processo com alteração no parâmetro de oportunidade tecnológica}

Ao contrário do observado no caso de um setor intensivo em inovação de produto, a mudança de parâmetros efetuada promoveu menor concentração de mercado e menor dispersão em termos de variáveis de desempenho competitivo, tal como market share, entre as empresas (Figura 6). 
Tabela 5

Condições iniciais - Setor intensivo em inovação de processo

\begin{tabular}{|c|c|c|c|c|c|c|c|c|}
\hline \multicolumn{9}{|c|}{ Mercado } \\
\hline Oportunidade tecnológica para inovação de processo & 0.004 & & & & & & & \\
\hline Velocidade do aprendizado & 0.025 & & & & & & & \\
\hline Oportunidade tecnológica para inovação de produto & 0.001 & & & & & & & \\
\hline Elasticidade-preço da competitividade & 0.75 & & & & & & & \\
\hline Elasticidade-qualidade da competitividade & 0.50 & & & & & & & \\
\hline Firma & F1 & F2 & F3 & F4 & F5 & F6 & F7 & F8 \\
\hline Parcela da receita gasta com inovação de processo & 0.03 & 0.03 & 0.03 & 0.01 & 0.01 & 0.00 & 0.00 & 0.00 \\
\hline Parcela da receita gasta com imitação de processo & 0.01 & 0.01 & 0.01 & 0.03 & 0.03 & 0.03 & 0.03 & 0.03 \\
\hline Parcela da receita gasta com inovação de produto & 0.01 & 0.01 & 0.01 & 0.01 & 0.01 & 0.00 & 0.00 & 0.00 \\
\hline Parcela da receita gasta com imitação de produto & 0.01 & 0.01 & 0.01 & 0.01 & 0.01 & 0.01 & 0.01 & 0.01 \\
\hline Parâmetro $\gamma$ (equação de salário) & 0.75 & 0.75 & 0.75 & 0.75 & 0.75 & 0.75 & 0.75 & 0.75 \\
\hline Parâmetro $\Theta$ (equação de preço) & 0.70 & 0.70 & 0.70 & 0.60 & 0.60 & 0.30 & 0.30 & 0.30 \\
\hline
\end{tabular}

Neste caso, o aumento da produtividade latente reforça o efeito de aprendizado, o que faz da busca imitativa uma estratégia bem-sucedida não apenas para a sobrevivência das firmas imitadoras, mas também para tirá-las da posição de retardatárias, aproximando-as das inovadoras em termos da geração de excedente bruto e ganho de market share. Não há grande divergência na distribuição da renda setorial entre salários e excedente bruto, pois da mesma forma que o excedente, os salários também apresentam uma trajetória de expansão e baixa dispersão entre as firmas. O teste de comparação de médias para amostras pareadas (Anexo) mostrou que os resultados das simulações envolvendo um setor intensivo em inovação de processo (sem alterações dos parâmetros ambientais) e outro setor também intensivo em inovação de processo (com alteração nos parâmetros ambientais) são estatisticamente diferentes (estatística $\mathrm{t}=$ - 4.164), considerando um nível de confiança de $95 \%$. O aumento da produtividade latente em relação à qualidade latente, de fato, promove resultados de simulações distintos, ainda que não altere de forma significativa a distribuição setorial funcional da renda. Dessa forma, um ambiente competitivo caracterizado por maior oportunidade tecnológica para inovação de processo em relação à oportunidade tecnológica para inovação de produto não é capaz de gerar desvios distributivos importantes, por não alterar uma das mais importantes variáveis estruturais, o mark-up. 
Figura 6

Market share, excedente bruto, salário, distribuição setorial funcional da renda e concentração de mercado em um setor intensivo em inovação de processo

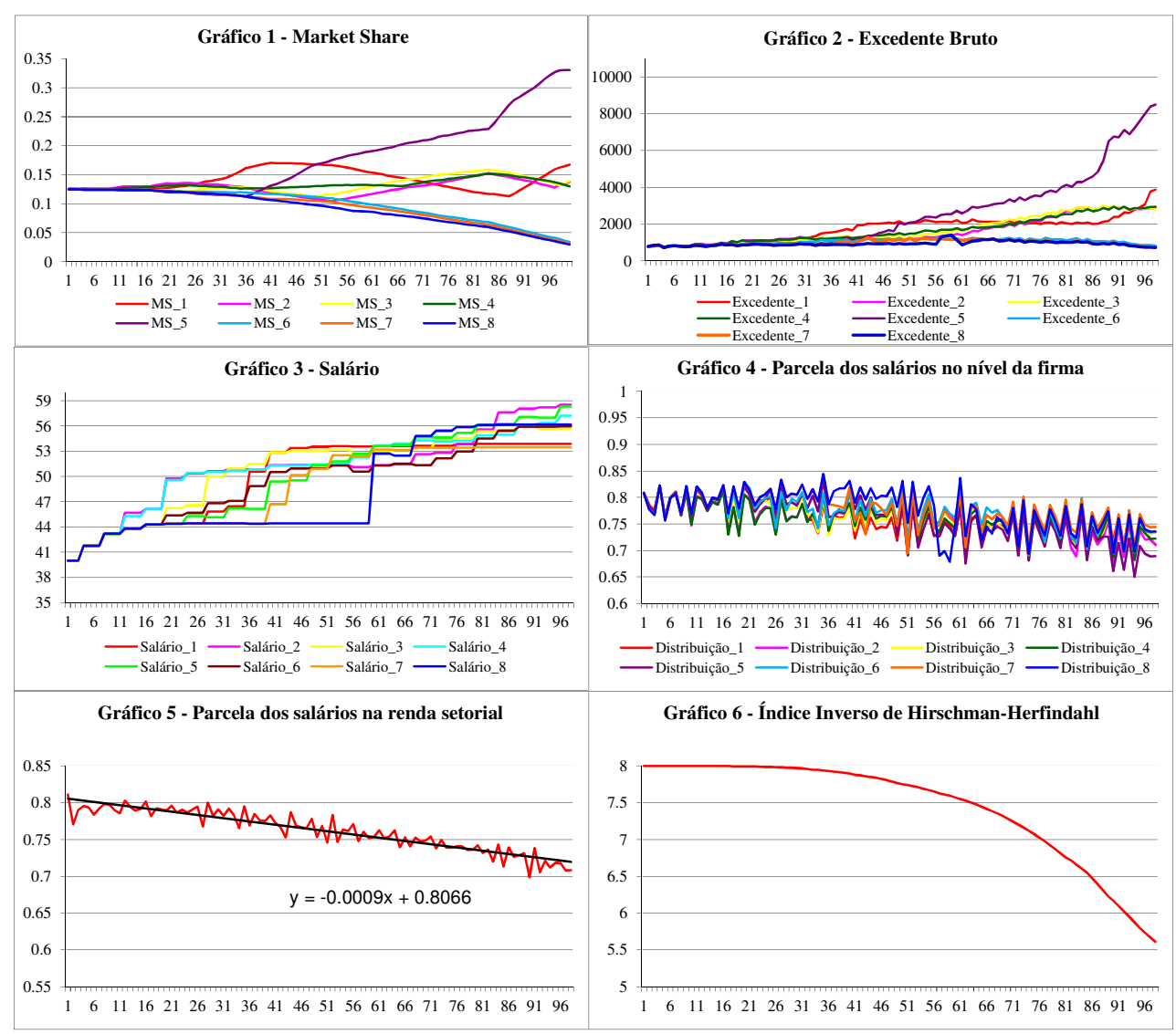

As simulações apresentadas nas Figuras 5 e 6 representam, respectivamente, setores intensivos em inovação de produto e processo envolvendo variações em dois parâmetros ambientais: (a) oportunidade tecnológica para inovação de produto; (b) oportunidade tecnológica para inovação de processo. As alterações ambientais propostas mostraram que a ampliação da diferença entre estes dois parâmetros de oportunidade tecnológica tem impactos sobre a distribuição setorial funcional da renda. A diferença observada na trajetória da distribuição setorial funcional da renda entre os dois setores simulados, tal como na estrutura de parâmetros anterior (itens 4.2.1 e 4.2.2), deve-se à possibilidade de as firmas que atuam no setor intensivo em inovação de produto aumentarem seus níveis de mark-up desejado (Figura 7). De fato, o teste de comparação de médias para amostras pareadas (Anexo) mostra que os resultados obtidos nas simulações envolvendo um setor intensivo em inovação de processo e um setor intensivo em inovação de produto, ambos com alterações nos parâmetros ambientais, são estatisticamente diferentes. Portanto, o aumento da 
oportunidade tecnológica para inovação de produto ao ampliar mark-ups, altera a distribuição funcional setorial da renda. Em um ambiente com elevada taxa de crescimento da qualidade latente em relação à taxa de crescimento da produtividade latente, o ganho competitivo proveniente de incrementos da qualidade dos produtos, levando ao aumento de preços, permite às firmas inovadoras praticarem uma política de elevação do mark-up desejado, aumentando a apropriação dos ganhos de competitividade e elevando significativamente a participação do excedente bruto na renda gerada em detrimento dos salários.

Figura 7

Mark-up desejado - setor intensivo em inovação de produto e setor intensivo em inovação de processo, com alteração nos parâmetros ambientais
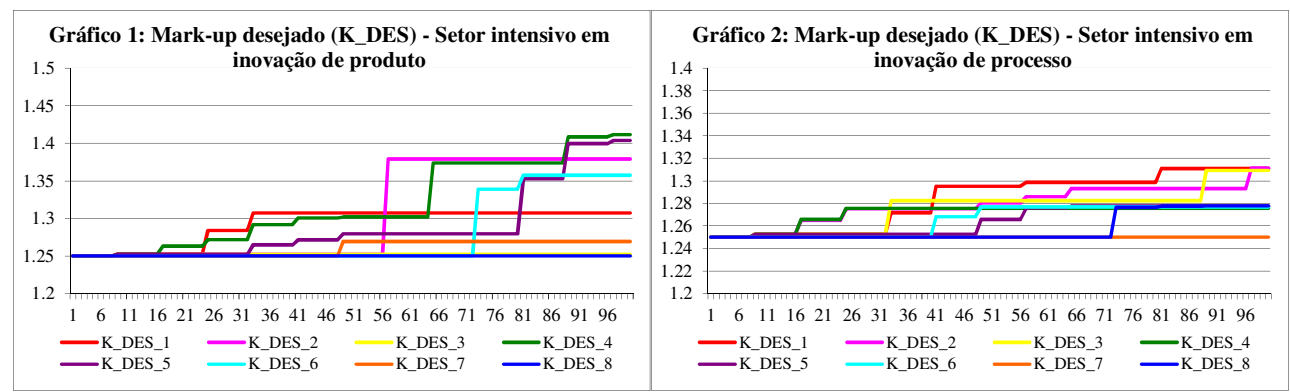

Ainda que os ganhos de produtividade fossem integralmente repassados para os salários $(\gamma=1)$, o aumento da participação do excedente bruto na renda setorial seria mais evidente no setor intensivo em inovação de produto, com taxa de crescimento da qualidade latente bem superior ao crescimento da produtividade latente. As simulações mostradas na Figura 8 foram feitas utilizando as mesmas condições iniciais apresentadas na Tabela 4 para um setor intensivo em inovação de produto, com a diferença que o parâmetro $(\gamma)$ de repasse dos ganhos de produtividade para os salários possui valor 1 , ao invés do valor 0,75 suposto nas simulações anteriores.

Figura 8

Mark-up desejado e distribuição setorial funcional da renda, setor intensivo em inovação de produto, repasse integral dos ganhos de produtividade $(\gamma=1)$

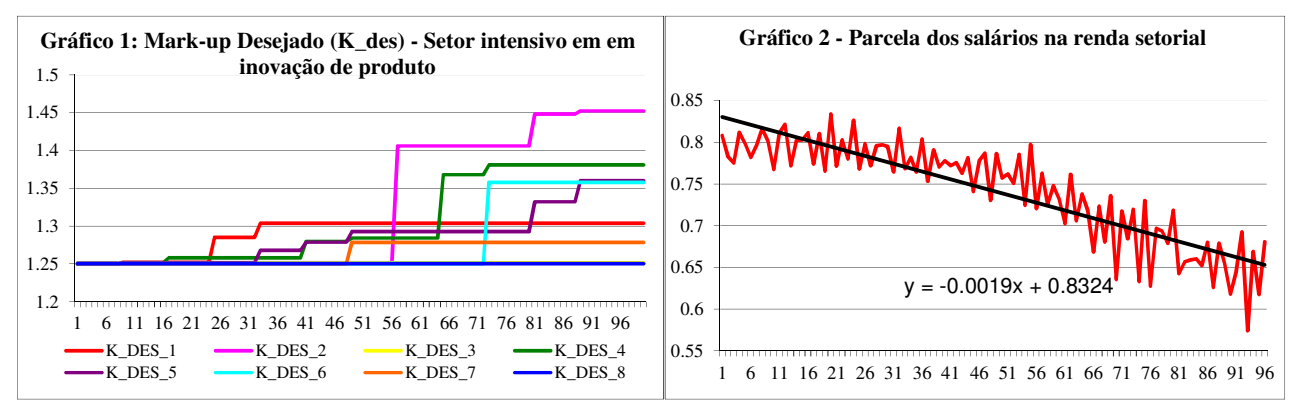


O aumento do repasse dos ganhos de produtividade para os salários não impede a redução da parcela destes na renda setorial, pois o crescimento dos salários não acompanha o crescimento da renda setorial. $O$ teste de comparação de médias para amostras pareadas (Anexo) revela que a comparação entre os resultados das simulações obtidas em dois cenários distintos para um setor intensivo em inovação de produto - o primeiro cenário apresentando repasse parcial dos ganhos de produtividade para os salários $(\gamma=0.75)$; o segundo com repasse integral dos ganhos de produtividade para os salários $(\gamma=1)$ - são estatisticamente diferentes, com confiança de $95 \%$. Portanto, ainda que os ganhos de produtividade sejam integralmente repassados para os salários, não há um aumento da parcela dos salários na renda setorial. É possível concluir daí que o fator que promove os efeitos distributivos observados não está atrelado à política salarial adotada, e sim à geração de ganhos competitivos, isto é, às condições de oportunidade tecnológica para inovação de produto e a estratégia de busca inovativa das firmas. A apropriação de ganhos derivados de vantagens competitivas por parte da firma não é em princípio afetada por uma alteração na política de repasse dos ganhos de produtividade para os salários ${ }^{20}$, sob a premissa de aumento do seu mark up desejado. Ao contrário, é possível que a empresa aumente salários e ainda assim ocorra aumento na participação do lucro na renda se o mark-up puder aumentar.

Figura 9

Market share, excedente bruto, salário e concentração de mercado em um setor intensivo em inovação de produto $(\operatorname{com} \gamma=1)$

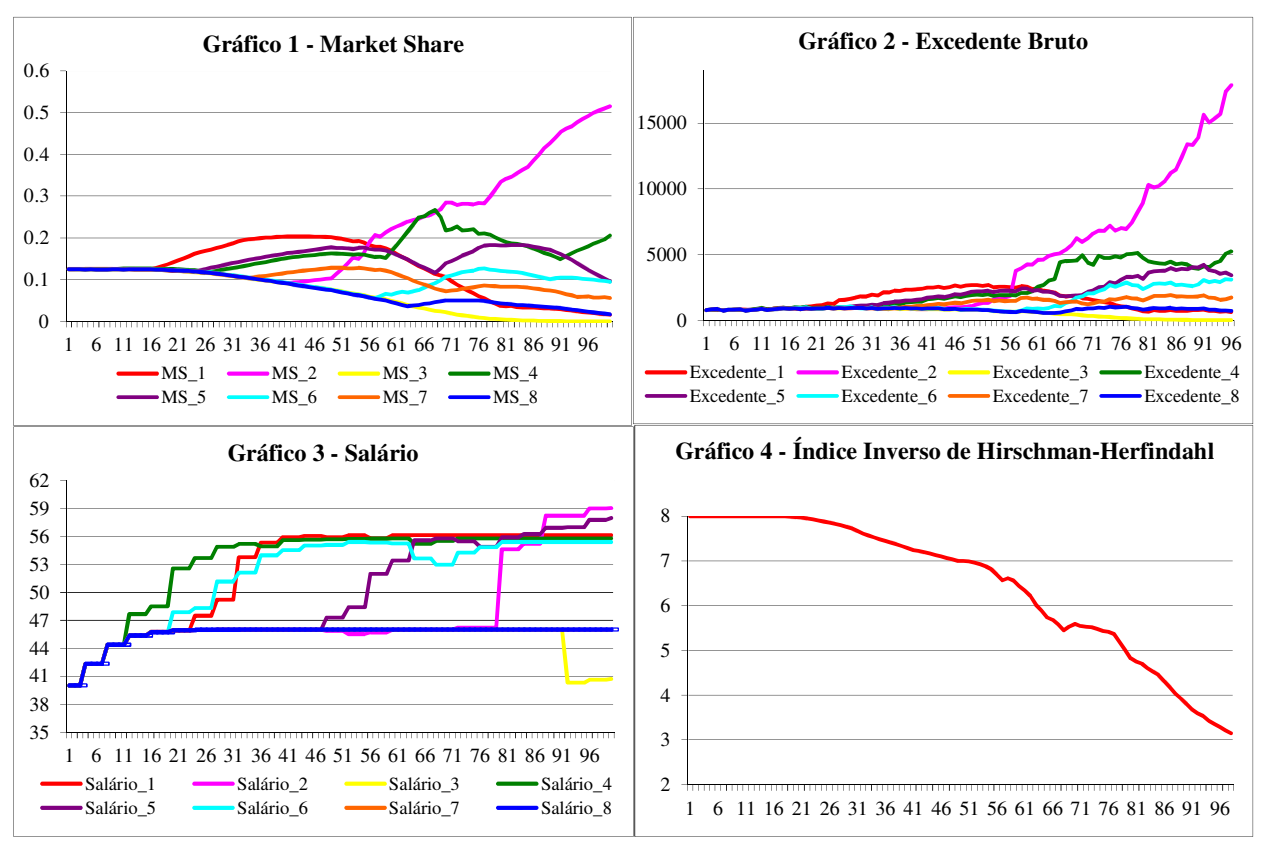

(20) A menos que houvesse simultaneamente um aumento do poder de barganha dos assalariados expresso numa redução do mark-up apesar dos ganhos competitivos, o que seria uma circunstância inteiramente exógena à presente análise. 
Na Figura 9 observa-se que há uma grande divergência entre o excedente bruto da firma melhor posicionada no mercado e as demais, justificando a trajetória declinante da participação dos salários na renda setorial e a concentração do mercado.

As simulações a seguir apresentam as mesmas condições iniciais da Tabela 5 para um setor intensivo em inovação de processo, novamente com a diferença de que é suposto $\gamma=1$. Neste caso, o aumento dos salários nominais pelo repasse integral dos ganhos de produtividade não afeta a participação dos salários na renda setorial. Neste caso, o maior poder de mercado expresso num mark-up crescente é suficiente para anular os efeitos positivos do aumento de salários sobre sua participação na renda setorial.

Figura 10

Mark-up desejado e distribuição setorial funcional da renda em um setor intensivo em inovação de processo $(\operatorname{com} \gamma=1)$



Ao contrário do setor intensivo em inovação de produto, aqui não houve alterações na concentração do mercado nem aumento da dispersão dos market shares e excedentes brutos entre as firmas inovadoras e imitadoras. Todas as firmas conseguiram manter uma trajetória ascendente tanto do excedente bruto quanto dos salários, possibilitando o surgimento de certa estabilidade da distribuição setorial funcional da renda ao longo da simulação.

As simulações a seguir apresentam as mesmas condições iniciais da Tabela 4 para um setor intensivo em inovação de produto, com a diferença de que o parâmetro $(\gamma)$ de determinação do repasse dos ganhos de produtividade para salários foi reduzido para 0,5 .

Neste caso, observa-se que não houve nenhuma diferença expressiva na distribuição setorial funcional da renda entre estes resultados e os obtidos nas simulações apresentadas na Figura 8, em que os ganhos de produtividade são integralmente repassados para os salários. Este fato reforça a percepção de que tal distribuição, sobretudo nos setores cujas empresas têm ganhos de competitividade e de poder de mercado suficientes para elevar seu grau de monopólio, não é afetada por alterações na política salarial, mas sim pelos fatores que influenciam o mark-up 
das firmas, tais como a introdução de inovações de produto que permitam reforçar sua posição oligopolista, aumentando seu mark-up sem comprometer o market share.

Figura 11

Market share, excedente bruto, salário e concentração de mercado em um setor intensivo em inovação de processo $(\operatorname{com} \gamma=1)$

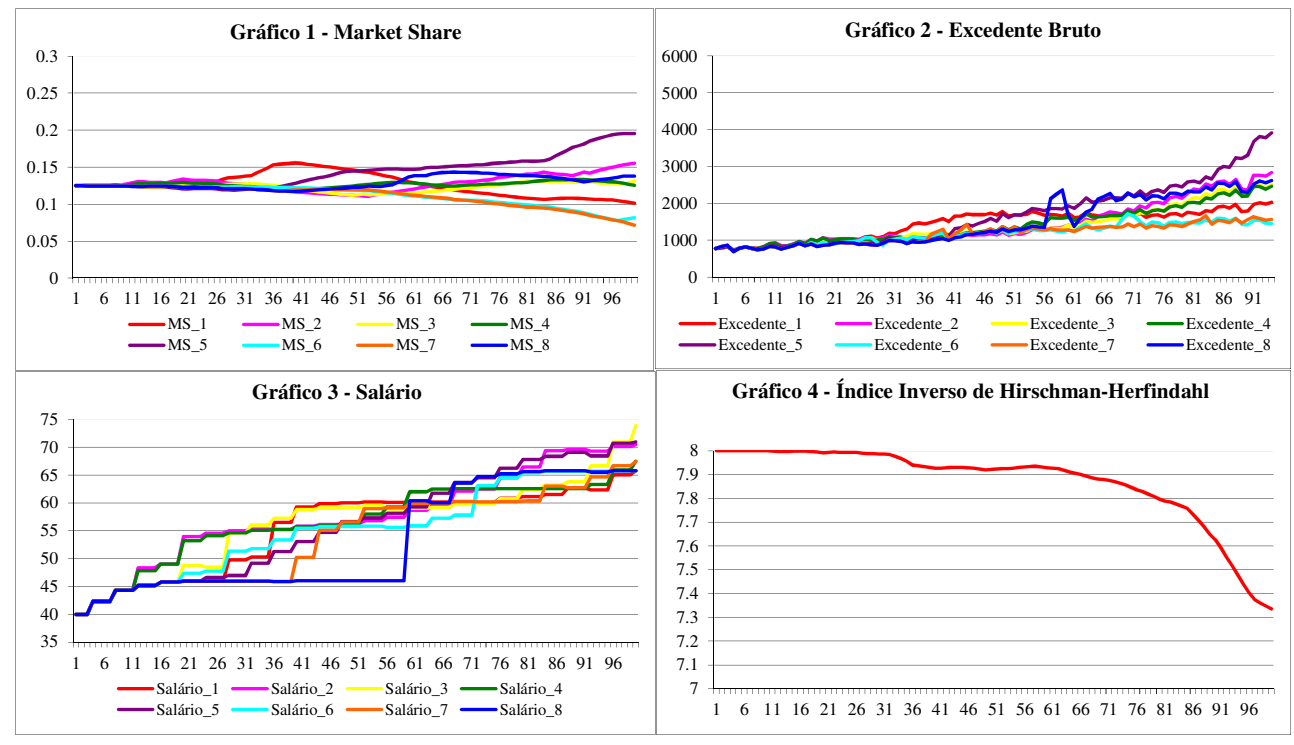

Figura 12

Mark-up desejado e distribuição setorial funcional da renda em um setor intensivo em inovação de produto $(\operatorname{com} \gamma=0,5)$

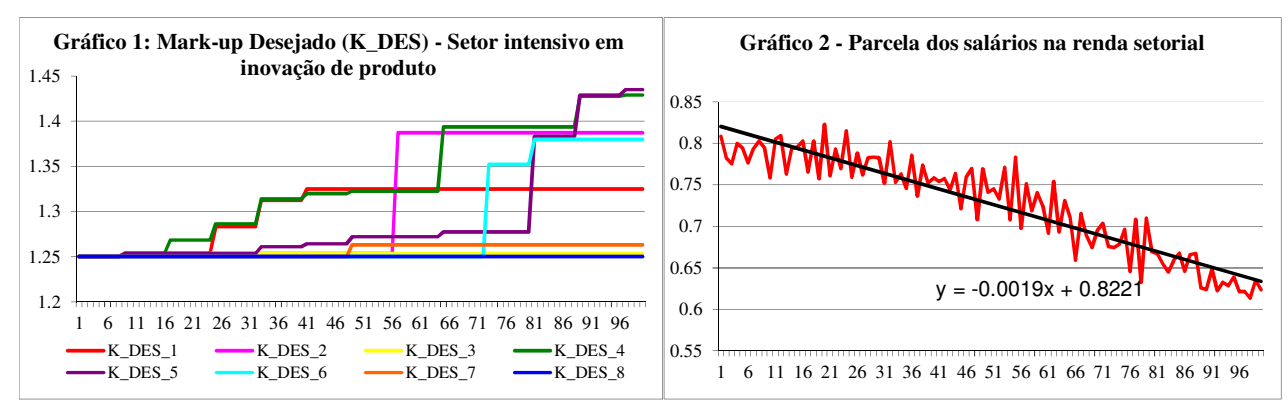

Os resultados das simulações apresentados nas Figuras 8 e 12 seguem a teoria distributiva Kaleckiana, segundo a qual o mark-up é o principal fator distributivo, na medida em que, dado o seu caráter estrutural, reflete a posição competitiva do produtor vis-à-vis a estrutura dos mercados com que se relaciona a montante e a jusante, o que supõe, entre outros aspectos, sua relativa insensibilidade a mudanças conjunturais nas condições de demanda por sucessivos períodos. A análise da influência do mark-up sobre a parcela dos salários na renda permite 
identificar as condições estruturais, isto é, os aspectos tecnológicos, produtivos e de poder de mercado, que podem promover alterações na distribuição setorial funcional da renda.

Em Kalecki (1954, cap. 1), uma elevação do grau de monopólio ou dos preços das matérias-primas com relação aos custos salariais provoca a queda da parcela relativa dos salários no valor agregado. Como a razão entre os preços das matérias-primas e os custos salariais depende da demanda de matérias-primas em relação à sua oferta, a qual é inelástica no curto prazo, o único fator estratégico e, portanto, passível de alteração em função da estratégia de busca tecnológica adotada pela firma, na determinação da parcela dos salários na renda gerada é o mark-up.

Para Possas (1983), a importância da relação entre os preços das matériasprimas e os custos salariais deve-se à representação dos efeitos inter-setoriais, implícitos nesta relação, dos preços dos produtos intermediários sobre a estrutura de custos diretos do estágio produtivo em análise. Como o modelo utilizado neste artigo é setorial, os possíveis efeitos do comportamento dos preços das matérias-primas sobre os preços praticados pelos setores estilizados não são considerados - o preço das matérias-primas é determinado como um parâmetro - dada a impossibilidade de considerar as relações inter-setoriais em um modelo restrito a um setor. Segundo o autor, a razão preços das matérias-primas e custos salariais considerada na análise distributiva Kaleckiana mostra que a distribuição, mesmo se tratada analiticamente a partir do nível de empresas ou indústrias, não é independente da inter-relação do sistema de preços ditada pela estrutura global do sistema produtivo.

No modelo, o custo da matéria-prima por unidade de produção é definido como um parâmetro e, portanto, um aumento do salário nominal reduz a relação entre os preços das matérias-primas e os custos de salários, o que, de acordo com a teoria Kaleckiana, tem um efeito positivo sobre a participação dos salários na renda setorial. Porém, ao comparar as simulações apresentadas na Figura $8 \mathrm{com}$ aquelas da Figura 12 , observa-se que esta participação não é alterada pelo menor repasse dos ganhos de produtividade para os salários, sugerindo que a manutenção de crescentes markups por parte das firmas em um setor intensivo em inovação de produto cancela eventuais efeitos positivos do aumento dos salários nominais sobre a participação destes na renda setorial gerada.

\section{Conclusão}

A principal conclusão extraída deste trabalho é que os resultados obtidos a partir das simulações desenvolvidas nos três tipos de setores estilizados - (i) setor com inovação de processo e sem inovação de produto; (ii) setor intensivo em inovação de produto; (iii) setor intensivo em inovação de processo - corroboram a teoria distributiva kaleckiana, segundo a qual a determinação da distribuição 
funcional da renda se dá à luz do processo de formação de preços em mercados regidos por mark-up, e a estendem para situações em que os avanços tecnológicos obtidos com o processo inovativo, ao influenciar preço e mark-up, afetam diretamente a distribuição. Dessa forma, o aumento do poder de monopólio das firmas, alcançado por meio de uma estratégia de busca inovativa intensiva em inovação de produto, impede que um eventual repasse integral dos ganhos de produtividade para os salários nominais exerça efeito positivo sobre a parcela dos salários na renda setorial.

A inovação, seja de processo ou de produto, somente acarreta alterações distributivas na medida em que amplia as assimetrias entre as firmas, isto é, aumenta as diferenças entre firmas inovadoras e imitadoras. Quando o efeito de aprendizado permite às imitadoras manterem fatias de mercado próximas às obtidas pelas firmas inovadoras, alterações distributivas não são observadas, como no caso da simulação em condições-padrão. Isso ocorre porque quando o efeito de aprendizado é suficientemente alto para amenizar a emergência de grande diversidade no mercado, causada pela inovação, não há grande variabilidade entre os excedentes brutos das firmas inovadoras e imitadoras, bem como entre os market shares, impedindo, dessa forma, o aumento da participação do excedente bruto, em detrimento dos salários, na renda setorial.

Em um setor intensivo em inovação de produto, a forma como a renda setorial é distribuída, privilegiando a participação dos excedentes brutos, sugere que quanto mais elevado o crescimento da qualidade latente, maior a possibilidade das firmas inovadoras exercerem seu poder de mercado, em função da competição por maior qualidade dos produtos, tornando possível a estas firmas aumentarem o preço sem comprometer market share. O aumento nos parâmetros de oportunidade tecnológica para inovação de produto e inovação de processo beneficia as firmas inovadoras e os efeitos do aprendizado tecnológico não são suficientes para amenizar a vantagem competitiva das inovadoras em relação às imitadoras.

O aumento do parâmetro de oportunidade tecnológica para inovação de produto reforça as vantagens competitivas das firmas inovadoras, ampliando as assimetrias entre os grupos de firmas inovadoras e imitadoras e amenizando os efeitos do aprendizado tecnológico, responsáveis pela sobrevivência e rentabilidade das firmas imitadoras. Neste contexto, a apropriação dos benefícios econômicos da inovação para os lucros é aumentada, enquanto a participação dos salários na renda setorial é reduzida. Este efeito distributivo é observado mesmo sob a condição de repasse integral dos ganhos de produtividade para os salários $(\gamma=1)$.

Por outro lado, a elevação do parâmetro de oportunidade tecnológica para inovação de processo não promove grande dispersão das variáveis de desempenho competitivo, tais como market share e excedente bruto, entre as empresas. Conclui- 
se que, neste caso, o aumento da produtividade latente reforça os efeitos de aprendizado tecnológico, permitindo que as firmas imitadoras acompanhem o desenvolvimento competitivo das inovadoras. Como consequência, a concentração se mantém baixa e não há grande divergência na distribuição da renda setorial entre salários e lucros. Além disso, como a competição em preço é uma estratégia predominante nesses setores, o aumento dos mark-ups (expressando maior poder de mercado) não ocorre com a intensidade observada no caso de um setor intensivo em inovação de produto.

\section{Bibliografia}

AFUAH, A. N.; UTTERBACK J. M. Responding to structural industry changes: a technological evolution perspective. Industrial and Corporate Change, v. 6, p. 183202, 1997.

ARTHUR, W. B. Out-of-equilibrium economics and agent-based modeling. In: JUDD, K.; TESFATSION, L. (Ed.). Handbook of computational economics. v. 2: Agent-based computational economics. Amsterdam: Elsevier/North-Holland, 2005.

AXELROD, R. Advancing the art of simulation in the social sciences. In: RENNARD, J. P. (Ed.). Handbook of research on nature inspired computing for economy and management. Hershey: Idea Group, 2005.

CYERT, R. M.; MARCH, J. G. A behavioral theory of the firm. New Jersey: Englewood Cliffs, 1963.

CORSINO, M.; GABRIELE, R. Product innovation and firm growth: evidence from the integrated circuit industry. Industrial and Corporate Change, v. 20, p. 29-56, 2010 .

DAWID, H. Agent-based models of innovation and technological change. In: JUDD, K.; TESFATSION, L. (Ed.). Handbook of computational economics. v. 2: Agentbased computational economics. Amsterdam: Elsevier/North-Holland, 2005.

DANEELS, E. The dynamics of product innovation and firm competences. Strategic Management Journal, 23, p. 1095-1121, 2002.

DAMANPOUR, F.; GOPALAKRISHNAN, S. The dynamics of the adoption of product and process innovation in organizations. Journal of Management Studies, 38, p. 45-65, 2001.

DOSI, G. Sources, procedures, and microeconomic effects of innovation. Journal of Economic Literature, 26, p. 1120-1171, 1988.

; PAVITT K.; SOETE, L. The economics of technical change and international trade. New York: New York University Press, 1990. 
DOSI, G.; MALERBA, F.; MARSILI, O.; ORSENIGO, L. Industrial structures and dynamics: evidence, interpretations and puzzles. Industrial and Corporate Change, 6, p. 5-24, 1996.

DOUGHERTY, D. Interpretive barriers to successful product innovation in large firms. Organization Science, 3, p. 179-202, 1992.

DWECK, E. Uma análise da interação micro-macro com base em um modelo dinâmico multissetorial de simulação. 2006. Tese (Doutorado)-Instituto de Economia (IE), UFRJ, Rio de Janeiro, 2006.

EISENHARDT, K. M.; TABRIZI, B. N. Accelerating adaptative process: product innovation in the global computer industry. Administrative Science Quartely, 40, p. 84-110, 1995.

GARSON, G. D. Computerized simulation in the social sciences: a survey and evaluation. Simulation and Gaming, 4, p. 267-279, 2009.

KALECKI, M. Theory of economic dynamics. $2^{\text {nd }}$ ed. London: Allen \& Unwin, 1954.

MALERBA, F. Learning by firms and incremental technical change. The Economic Journal, 102, p. 845-859, 1992.

NELSON, R.; WINTER S. An evolutionary theory of economic change. Cambridge: Harvard University, 1982.

NONAKA, I. A dynamic theory of organization knowledge creation. Organization Science, 5, p. 14-37, 1994.

PLEATSIKAS, C.; TEECE D. The analysis of market definition and market power in the context of rapid innovation. International Journal of Industrial Organization, 19, p. 665-693, 2001.

POSSAS, M. L. Dinâmica e ciclo econômico em oligopólio. 1983. Tese (Doutorado)-Instituto de Economia (IE), Unicamp, Campinas, 1983.

POSSAS, M. L.; KOBLITZ, A.; LICHA, A.; OREIRO, J. L.; DWECK, E. Um modelo evolucionário setorial. Revista Brasileira de Economia, 55, p. 333-377, 2001.

SAVIOTTI, P. P. Variety, growth and demand. Journal of Evolutionary Economics, 11, p. 119-142, 2001.

SAVIOTTI, P. P.; PYKA, A. Micro and macro dynamics: industry life cycles, intersector coordination and aggregate growth. Journal of Evolutionary Economics, 18, p. $167-182,2008$. 
SILVERBERG, G. Technical progress, capital accumulation and effective demand: a self-organization model. In: BATTEN, D.; CASTI, J.; JOHANSSON, B. (Ed.). Economic evolution and structural adjustment. Berlin: Springer-Verlag, 1987.

SILVERBERG, G.; DOSI, G.; ORSENIGO, L. Innovation, diversity and diffusion: a self-organization model. The Economic Journal, 38, p. 1032-1054, 1988.

STORPER, M. Innovation as collective action: conventions, products and technologies. Industrial and Corporate Change, 5, p. 761-790, 1996.

SCHUMPETER, J. Capitalism, socialism and democracy. London: George Allen \& Unwin, 1943.

UTTERBACK, J. M. Mastering the dynamics of innovation. Boston: Harvard Business School Press, 1994.

VALENTE, M. Evolutionary economics and computer simulation: a model for the evolution of markets. 1999. PhD in Economics - University of Aalborg, Aalborg, 1999.

VERONA, G.; RAVASI, D. Unbundling dynamic capabilities: an exploratory study of continuous product innovation. Industrial and Corporate Change, 12, p. 557-606, 2003. 
Um modelo setorial baseado na abordagem kaleckiana da distribuição setorial funcional da renda...

\section{Anexo}

Teste de Comparação de Médias para Amostras Pareadas

Variável de análise: Participação dos salários na renda setorial (diferentes cenários de simulação)

\begin{tabular}{|c|c|c|c|c|}
\hline$\frac{\text { Variável }}{\text { Participação dos salários na renda setorial }}$ & Mean & $\begin{array}{l}\text { Standard } \\
\text { deviation }\end{array}$ & $\begin{array}{l}\text { Standard } \\
\text { error } \\
\text { mean }\end{array}$ & $\begin{array}{c}\text { Test } \\
\text { statistic } \\
\text { (t) }\end{array}$ \\
\hline $\begin{array}{c}\text { Setor em condições-padrão } \\
X \\
\text { Setor intensivo em inovação de produto }\end{array}$ & 0.0070 & 0.02147 & 0.00215 & 3.256 \\
\hline $\begin{array}{c}\text { Setor em condições-padrão } \\
\text { X } \\
\text { Setor intensivo em inovação de processo }\end{array}$ & 0.0001 & 0.01513 & 0.00151 & 0.097 \\
\hline $\begin{array}{c}\text { Setor intensivo em inovação de produto } \\
\text { (sem alteração nos parâmetros ambientais) }^{\mathrm{a}} \\
\mathrm{X} \\
\text { Setor intensivo em inovação de produto } \\
\text { (com alteração nos parâmetros ambientais) }^{\mathrm{b}}\end{array}$ & 0.0083 & 0.01030 & 0.00103 & 8.102 \\
\hline $\begin{array}{c}\text { Setor intensivo em inovação de processo } \\
\text { (sem alteração nos parâmetros ambientais) }^{\mathrm{a}} \\
\mathrm{X} \\
\text { Setor intensivo em inovação de processo } \\
\text { (com alteração nos parâmetros ambientais) }^{\mathrm{b}}\end{array}$ & -0.0038 & 0.00902 & 0.00090 & -4.164 \\
\hline $\begin{array}{c}\text { Setor intensivo em inovação de produto } \\
\text { (com alteração nos parâmetros ambientais) }^{\mathrm{b}} \\
\mathrm{X} \\
\text { Setor intensivo em inovação de processo } \\
\text { (com alteração nos parâmetros ambientais) }^{\mathrm{c}}\end{array}$ & -0.0189 & 0.02225 & 0.00222 & -8.515 \\
\hline $\begin{array}{l}\text { Setor intensivo em inovação de produto } \\
\qquad(\gamma=0.75)^{\mathrm{d}} \\
\mathrm{X} \\
\text { Setor intensivo em inovação de produto } \\
(\gamma=1.00)^{\mathrm{e}}\end{array}$ & 0.0095 & 0.03052 & 0.00305 & 3.108 \\
\hline
\end{tabular}

Notas: Resultados obtidos para nível de confiança de $95 \%$.

a: parâmetros ambientais (oportunidade tecnológica para inovação de produto $=0.003$; oportunidade tecnológica para inovação de processo $=0.002$ )

b: parâmetros ambientais (oportunidade tecnológica para inovação de produto $=0.004$; oportunidade tecnológica para inovação de processo $=0.001$ )

c: parâmetros ambientais (oportunidade tecnológica para inovação de produto $=0.001$; oportunidade tecnológica para inovação de processo $=0.004$ )

d: Parâmetro de repasse dos ganhos de produtividade para os salários $(\gamma=0.75)$

e: Parâmetro de repasse dos ganhos de produtividade para os salários $(\gamma=1.00)$ 